Vol. 35, dezembro 2015, DOI: 10.5380/dma.v35i0.43542

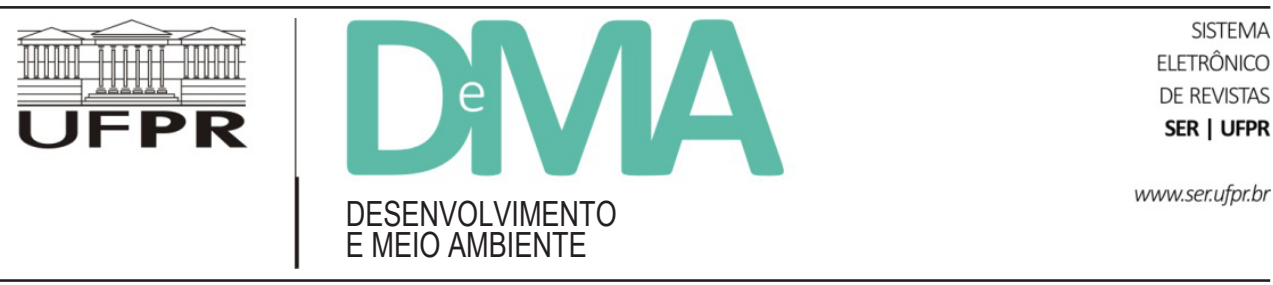

\title{
"Grito de la tierra, grito de los pobres", la propuesta ética de Francisco: una recuperación de los aportes latinoamericanos a la construcción de nuestra Casa Común
}

\author{
"Grito da terra, grito dos pobres", a proposta ética de Francisco: \\ uma recuperação dos aportes latino-americanos \\ na construção de nossa Casa Comum
}

\section{"Scream of the Earth, the Poor Scream", Ethics Proposed Francisco: a Recovery in Latin American Contributions in the Construction of our Common Home}

\author{
Antonio ELIZALDE ${ }^{1 *}$ \\ ${ }^{1}$ Universidad de los Lagos, Osorno, Chile. \\ *E-mail de contacto: antonio.elizalde@gmail.com \\ Artículo recibido el 16 de octubre, 2015, versión final aceptada el 4 de desembro, 2015.
}

RESUMEN: Se presenta la Encíclica Laudato si' y se la relaciona con dos documentos clave en el pensamiento socioambiental, uno de carácter global: La Carta de la Tierra; y el otro de origen latinoamericano El Manifiesto por la Vida. Se destaca el aporte que este documento hace al incorporar en el corpus doctrinal de la Iglesia Católica el tema del ambiente y al verlo sistémicamente vinculado con la inequidad, el consumismo, la exclusión social y la degradación ambiental, y al invitar a construir nuevas formas de entender la economía y el progreso y a desarrollar un nuevo estilo de vida.

Palabras clave: Laudato si'; Evangelii gaudium; Carta de la Tierra; manifiesto por la vida.

RESUMO: Apresentamos a Encíclica Laudato si'e a relacionamos com dois documentos-chave do pensamento socioambiental, o primeiro de caráter global, a Carta da Terra, e outro o Manifesto pela Vida, de origem latino-americana. Destaca-se a contribuição deste documento, incluindo a questão do ambiente ao corpus doutrinário da Igreja Católica e vendo-o sistemicamente ligado à desigualdade, ao consumismo, à exclusão social e à degradação ambiental no sentido de construir novas formas de compreensão da economia e do progresso dentro de um novo estilo de vida.

Palavras-chave: Laudato si'; Evangelii gaudium; Carta da Terra; manifesto pela vida. 
ABSTRACT: We present the Encyclical Laudato if' and relate it to two key documents of socio-environmental thinking, the first of global character: The Earth Letter; and the other of Latin American origin, The Manifest for Life. It highlights the contribution made by this document including the issue of environment in the doctrinal corpus of The Catholic Church and seeing systemically linked to inequality, consumerism, social exclusion and environmental degradation, and the call to build new ways of understanding the economy and progress into a new developed lifestyle.

Keywords: Laudato if'; Evangelii gaudium; Earth Charter; manifesto for life.

[...] basta mirar la realidad con sinceridad para ver que hay un gran deterioro de nuestra casa común. La esperanza nos invita a reconocer que siempre hay una salida, que siempre podemos reorientar el rumbo, que siempre podemos hacer algo para resolver los problemas. Sin embargo, parecen advertirse síntomas de un punto de quiebre, a causa de la gran velocidad de los cambios y de la degradación, que se manifiestan tanto en catástrofes naturales regionales como en crisis sociales o incluso financieras, dado que los problemas del mundo no pueden analizarse ni explicarse de forma aislada. Hay regiones que ya están especialmente en riesgo y, más allá de cualquier predicción catastrófica, lo cierto es que el actual sistema mundial es insostenible desde diversos puntos de vista, porque hemos dejado de pensar en los fines de la acción humana. Laudato si', (61) Francisco Primero

\section{Introducción}

Considero necesario señalar desde donde me sitúo al presentar las reflexiones que busco compartir en este artículo. Creo que la gravedad de los problemas sociales y ambientales que estamos enfrentando son de tal magnitud que es fundamental, desde una perspectiva ético política, sumar fuerzas, agregar voluntades y convicciones, dadas las urgencias y la magnitud de los esfuerzos que será necesario desarrollar para lograr revertir el rumbo suicida en el cual como humanidad estamos embarcados.

Años atrás, Humberto Maturana al prologar mi libro Desarrollo humano y ética para la sustentabilidad señaló lo siguiente:

Si de hecho nos diésemos cuenta de que vivimos enajenados en creernos seres primariamente racionales cuando lo fundamental es nuestro ser emocional, si de hecho nos diésemos cuenta de que la potencia y efectividad de nuestros argumentos racionales depende de las premisas básicas aceptadas a priori que los fundan y de los deseos que nos orientan en su uso, entonces, frente a una discrepancia con otro ya no buscaríamos más con-vencerlo con nuestros argumentos sino que solamente querríamos mostrar lo que entendemos en esa situación deseando inspirarlo a participar con nosotros en el uso de su emocionar y razonar para la cocreación de un convivir ético que sea deseable para ambos tanto como para la comunidad humana y ecológica de seres vivos que nos hace posibles y nos sostiene. Y lo haríamos seducidos por la conciencia de que un mundo así sólo es posible como un propósito compartido a modo de una obra de arte que se crea cotidianamente en el convivir de personas que quieren convivir en el respeto por sí mismos y por los otros. Y lo haríamos ante todo seducidos por el descubrimiento de que nosotros mismos somos nuestro mejor recurso para crear cotidianamente un mundo que sea biológicamente armónico para todos los seres humanos al habitar una biosfera que respetan porque los acoge y hace posibles. (2003, p. 20-21).

Tengo la convicción de que el principal problema que tenemos en las sociedades actuales es la enorme ceguera con la cual apreciamos la realidad de la cual formamos parte. Hay un imaginario instalado que no hemos sido capaces de modificar, ni siquiera de incidir significativamente en su transformación. Hay un mundo en el cual transcurre el espacio de la toma de decisiones que nos afectan a todos, el cual está absolutamente inmerso en las preocupaciones cortoplacistas del ejercicio del poder y de los negocios. En cierto grado sería posible afirmar que todos nos hemos empobrecido, contagiados por las hegemónicas concepciones economicistas que reducen todo a un juego de beneficios y costos monetarios, como lo señala Federico Aguilera Klink:

La economía que se enseña habitualmente en las universidades y que también se divulga de manera esquemática 
y repetitiva a través de los medios de comunicación, es una economía que empobrece intelectual y psíquicamente a los estudiantes e indirectamente al resto de los ciudadanos, a través de esa divulgación, acabando finalmente por deshumanizarlos o deshumanizarnos a todos. La razón es que esta economía se ha ido separando y disociando de las personas, de la naturaleza y de la ética, centrándose en una idea de agente racional, sinónimo de egoísta que sólo calcula en términos de beneficios y costes monetarios en un hipotético contexto de mercado libre, sinónimo de sin reglas, que legitima ese comportamiento y que se centra en el crecimiento económico, medido por el PIB, que se identifica interesadamente con el bienestar. En suma, es una economía que deja de estar al servicio del ser humano para ponerlo a su servicio mientras ignora la relación con la naturaleza y una toma de decisiones razonablemente éticas y democráticas [...] El resultado final es la legitimación (normalización) de un comportamiento disparatado y antisocial en el sentido de que ese comportamiento conduce a situaciones en las que las variables monetarias crecen pero ignorando que la realidad social y ambiental, humana en un sentido amplio, puede ser un auténtico desastre. Así pues los indicadores monetarios que corresponden a esa racionalidad económica nos indican simplemente la velocidad pero no la dirección hacia la que se camina. (2013, contracapa).

En razón de estas convicciones es que me ha parecido de gran importancia relevar el sustantivo aporte que hacen los documentos del Papa Francisco a los debates que es imprescindible impulsar en nuestras sociedades respecto al modelo de sociedad, de economía y de cultura, que el capitalismo globalizado ha ido instalando en el planeta y los cambios culturales y espirituales que requerimos para enfrentar la crisis socioambiental.

Hago manifiesto de inmediato que lo que pretendo en este artículo es examinar las perspectivas abiertas por el magisterio del Papa Francisco en dos documentos fundamentales para entender la dirección que busca imprimir a la institución que encabeza. La primera encíclica atribuible enteramente a la autoría del Papa Francisco, Laudato si', la cual continua la línea de orientación pastoral y teológica, abierta con la Exhortación Apostólica Evangelii gaudium, y que constituyen una excelente noticia y aporte al pensamiento y acción en pro de la sustentabilidad.

Paralelamente, pretendo también, aunque en un tono menor, destacar las coincidencias que su mensaje comparte con el corpus que ha ido constituyéndose como pensamiento socioambiental latinoamericano.

Como es de suponer estos textos han provocado una reacción alérgica entre los defensores del modelo global de acumulación del libre mercado, de las cuales presento algunas en el texto para graficar aquellos puntos que producen una mayor urticaria intelectual, en realidad más bien "ideológica." De modo similar y con el propósito de hacer patente las diferencias de acogida a estos planteamientos papales presentan un texto de destacados exponentes del pensamiento socioambiental.

\section{Presentación resumida de la Encíclica}

La encíclica consta de seis capítulos, es un texto apretado pero notablemente rico en contenidos. Ya el propio título indica una opción "franciscana", pues hace referencia a la oración poética de Francisco de Asís de alabanza a la creación. Incluso cuando fue elegido como pontífice sorprendió al mundo con el nombre que escogió y, apenas 3 días después de su elección, explicó por qué había elegido llamarse Francisco.

Y así, el nombre ha entrado en mi corazón: Francisco de Asís. Para mí es el hombre de la pobreza, el hombre

\footnotetext{
${ }^{1}$ Esta es la segunda encíclica publicada por Francisco, después de Lumen fidei, de 2013, sin embargo ésta fue escrita en gran parte por Benedicto XVI, por lo que Laudato si' es la primera encíclica escrita completamente por Francisco.

${ }^{2}$ Hago referencia a la escuela de pensamiento que es posible atribuir a Francisco de Asís. Creo necesario recordar que no sólo creó una orden religiosa, con una especificidad (vocación o carisma) de preocupación por los pobres y por la Naturaleza. Fue un adelantado a su época y marcó una preocupación sustantiva, al punto de dedicar su vida a ello, por los pobres y por la naturaleza (Creación haciendo uso del lenguaje teológico). "La solidaridad franciscana es amplia; proviene de una conciencia que se sabe responsable de todo el mundo y del respeto por la integridad de la creación: somos hermanos de todos los pueblos y de todas las culturas. Una solidaridad global es hoy aún más urgente porque las fuerzas del mercado de la economía global dan un significado distinto y trágico a las palabras de Jesús: "a quien tiene, se le dará más todavía [...], pero al que no tiene, se le quitará aun lo que tiene" (Mt 13,12)."
} 
de la paz, el hombre que ama y custodia la Creación; en este momento, también nosotros mantenemos con la creación una relación no tan buena, ¿no?

El cardenal Bergoglio, jesuita argentino, no sólo tomó el nombre del santo de Asís. Para esta primera encíclica escrita íntegramente por él y dedicada al medio ambiente, ha escogido como título "Alabado seas", las primeras palabras de El cántico de las criaturas de San Francisco de Asís.

El Papa Francisco lo considera un maestro en el cuidado de la Creación, al señalarlo así en la misa de inicio de su pontificado.

Es custodiar toda la creación, la belleza de la creación, como se nos dice en el libro del Génesis y como nos muestra san Francisco de Asís: es tener respeto por todas las criaturas de Dios y por el entorno en el que vivimos.

San Francisco de Asís escribió El cántico de las criaturas en torno a 1226, en dialecto de Umbria, cuando ya había iniciado su camino de pobreza radical. Es una expresión de alabanza a Dios a través de las criaturas y puede decirse que es uno de los primeros documentos ecologistas. En él, San Francisco de Asís habla del "hermano sol", el "hermano viendo", la "hermana agua", y la "hermana madre tierra". Su primera frase es "Alabado seas mi Señor, en todas tus criaturas". Además el cántico es considerado como el primer gran poema en lengua italiana.

Laudato si'(en latín); Alabado seas, en español, es el título de la segunda encíclica del papa Francisco, firmada el 24 de mayo, Solemnidad de Pentecostés del año 2015 y fue presentada a los medios de comunicación masivos el 18 de junio de 2015. Lleva como subtítulo: Sobre el cuidado de la casa común. Está compuesta por 246 párrafos divididos en seis capítulos, que agregan un nuevo aporte a la doctrina social de la Iglesia y pone a la humanidad frente a sus responsabilidades. Es un texto internamente muy articulado, y muy específico en diferentes puntos, que se fundamenta en los documentos producidos por muchas conferencias episcopales y que no se está dirigido no solo a los cristianos, sino "a cada persona que habita este planeta". Francisco da valor a las palabras de sus predecesores e invita a "eliminar las causas estructurales de las disfunciones de la economía mundial", corrigiendo los "modelos de crecimiento" que no han sido capaces de garantizar el respeto del medio ambiente.

La encíclica se centra en el planeta Tierra como lugar en el cual vivimos los seres humanos, defendiendo la naturaleza, la vida animal y las reformas energéticas en los seis capítulos que la componen. Francisco realiza allí una aguda y profunda crítica del consumismo y del desarrollo irresponsable con un alegato en favor de una acción mundial rápida y unificada "para combatir la degradación ambiental y el cambio climático".

Revisemos rápidamente la estructura de la parte introductoria del documento; la encíclica se inicia con la frase Laudato si' mi' Signore que hace referencia al Cántico de las criaturas escrito en el siglo XIII por San Francisco de Asís. Ya desde los párrafos iniciales es posible percibir la nueva mirada que nos propone para revincularnos con la naturaleza.

Los párrafos 3 al 6 que llevan como subtítulo "Nada de este mundo nos es indiferente" revisan el magisterio eclesial haciendo primero referencia a la encíclica Pacem in terris de Juan XXIII en momentos en los cuales el riesgo de un conflicto nuclear era muy grande y donde se hace un llamado a "todos los hombres de buena voluntad". Al igual que entonces señala que,

frente al deterioro ambiental global, quiero dirigirme a cada persona que habita este planeta. En mi exhortación Evangeliigaudium, escribí a los miembros de la Iglesia en orden a movilizar un proceso de reforma misionera todavía pendiente. En esta encíclica, intento especialmente entrar en diálogo con todos ${ }^{3}$ acerca de nuestra casa común.

Continúa recordando a Paulo VI, quien ya en 1971 en su Carta apostólica Octogesima adveniens,

Se refirió a la problemática ecológica, presentándola como una crisis, que es "una consecuencia dramática" de la actividad descontrolada del ser humano: "Debido

${ }^{3}$ El destacado es mío. 
a una explotación inconsiderada de la naturaleza, [el ser humano] corre el riesgo de destruirla y de ser a su vez víctima de esta degradación”. También habló a la FAO sobre la posibilidad de una "catástrofe ecológica bajo el efecto de la explosión de la civilización industrial", subrayando la "urgencia y la necesidad de un cambio radical en el comportamiento de la humanidad", porque "los progresos científicos más extraordinarios, las proezas técnicas más sorprendentes, el crecimiento económico más prodigioso, si no van acompañados por un auténtico progreso social y moral, se vuelven en definitiva contra el hombre".

En los párrafos siguientes recuerda afirmaciones de Juan Pablo II quien llamó a una conversión ecológica global salvaguardando las condiciones morales de una auténtica ecología humana y realizando cambios profundos en "los estilos de vida, los modelos de producción y de consumo, las estructuras consolidadas de poder que rigen hoy la sociedad" (Carta encíclica Centesimus annus (1 mayo 1991), y por último de su antecesor Benedicto XVI, quien en su Carta enciclíca Caritas in veritate (29 junio 2009) señaló que "la degradación de la naturaleza está estrechamente unida a la cultura que modela la convivencia humana".

En los párrafos 7 al 9 subtitulados "Unidos por la misma preocupación" hace referencia a las enseñanzas del Patriarca Ecuménico Bartolomé quien se ha referido particularmente,

a la necesidad de que cada uno se arrepienta de sus propias maneras de dañar el planeta, porque, "en la medida en que todos generamos pequeños daños ecológicos", estamos llamados a reconocer "nuestra contribución -pequeña o grande- a la desfiguración y destrucción de la creación"... Al mismo tiempo, Bartolomé llamó la atención sobre las raíces éticas y espirituales de los problemas ambientales, que nos invitan a encontrar soluciones no sólo en la técnica sino en un cambio del ser humano, porque de otro modo afrontaríamos sólo los síntomas. Nos propuso pasar del consumo al sacrificio, de la avidez a la generosidad, del desperdicio a la capacidad de compartir, en una ascesis que "significa aprender a dar, y no simplemente renunciar. Es un modo de amar, de pasar poco a poco de lo que yo quiero a lo que necesita el mundo de Dios. Es liberación del miedo, de la avidez, de la dependencia".
Los párrafos siguientes (10-12) se refieren a San Francisco de Asís, proponiéndolo como un modelo en un texto que pienso que resume la propuesta paradigmática que nos hace Francisco en su encíclica.

Tomé su nombre como guía y como inspiración en el momento de mi elección como Obispo de Roma. Creo que Francisco es el ejemplo por excelencia del cuidado de lo que es débil y de una ecología integral, vivida con alegría y autenticidad... En él se advierte hasta qué punto son inseparables la preocupación por la naturaleza, la justicia con los pobres, el compromiso con la sociedad y la paz interior. (10)

Su testimonio nos muestra también que una ecología integral requiere apertura hacia categorías que trascienden el lenguaje de las matemáticas o de la biología y nos conectan con la esencia de lo humano. Así como sucede cuando nos enamoramos de una persona, cada vez que él miraba el sol, la luna o los más pequeños animales, su reacción era cantar, incorporando en su alabanza a las demás criaturas... Su reacción era mucho más que una valoración intelectual o un cálculo económico, porque para él cualquier criatura era una hermana, unida a él con lazos de cariño. Por eso se sentía llamado a cuidar todo lo que existe... Esta convicción no puede ser despreciada como un romanticismo irracional, porque tiene consecuencias en las opciones que determinan nuestro comportamiento. Si nos acercamos a la naturaleza y al ambiente sin esta apertura al estupor y a la maravilla, si ya no hablamos el lenguaje de la fraternidad y de la belleza en nuestra relación con el mundo, nuestras actitudes serán las del dominador, del consumidor o del mero explotador de recursos, incapaz de poner un límite a sus intereses inmediatos. En cambio, si nos sentimos íntimamente unidos a todo lo que existe, la sobriedad y el cuidado brotarán de modo espontáneo. La pobreza y la austeridad de san Francisco no eran un ascetismo meramente exterior, sino algo más radical: una renuncia a convertir la realidad en mero objeto de uso y de dominio. (11)

Coincide casi totalmente con lo planteado por Leonardo Boff en el capítulo 11 "Todas las virtudes ecológicas: San Francisco de Asís" de su libro, Ecología: grito de la Tierra, grito de los pobres, publicado en 1996.

Aquí se deja ver otra manera de ser-en-el-mundo, distinta de la que criticábamos respecto de la modernidad. 
Ésta se sitúa por encima de las cosas para poseerlas o dominarlas, aquella, la de San Francisco, se pone a su lado para amarlas y convivir con ellas como hermanos y hermanas en una casa común. (1996, p. 262).

Los párrafos 13 al 16 llevan como subtítulo "Mi llamado" y se señala allí la urgencia de proteger nuestra casa común y de unir a toda la familia humana en la búsqueda de un desarrollo sostenible e integral, ya que las cosas pueden cambiar pues la humanidad aún posee la capacidad de colaborar para construir nuestra casa común. Alienta y agradece a quienes “están trabajando para garantizar la protección de la casa que compartimos" y en especial a "quienes luchan con vigor para resolver las consecuencias dramáticas de la degradación ambiental en las vidas de los más pobres del mundo." Agrega que "Los jóvenes nos reclaman un cambio. Ellos se preguntan cómo es posible que se pretenda construir un futuro mejor sin pensar en la crisis del ambiente y en los sufrimientos de los excluidos." (13)

Invita a realizar

un nuevo diálogo sobre el modo como estamos construyendo el futuro del planeta. Necesitamos una conversación que nos una a todos, porque el desafío ambiental que vivimos, y sus raíces humanas, nos interesan y nos impactan a todos. El movimiento ecológico mundial ya ha recorrido un largo y rico camino, y ha generado numerosas agrupaciones ciudadanas que ayudaron a la concientización. Lamentablemente, muchos esfuerzos para buscar soluciones concretas a la crisis ambiental suelen ser frustrados no sólo por el rechazo de los poderosos, sino también por la falta de interés de los demás. Las actitudes que obstruyen los caminos de solución, aun entre los creyentes, van de la negación del problema a la indiferencia, la resignación cómoda o la confianza ciega en las soluciones técnicas. Necesitamos una solidaridad universal nueva. (14)

En el párrafo siguiente (15) esboza el contenido del documento:

En primer lugar, haré un breve recorrido por distintos aspectos de la actual crisis ecológica, con el fin de asumir los mejores frutos de la investigación científica actualmente disponible, dejarnos interpelar por ella en profundidad y dar una base concreta al itinerario ético y espiritual como se indica a continuación. A partir de esa mirada, retomaré algunas razones que se desprenden de la tradición judío-cristiana, a fin de procurar una mayor coherencia en nuestro compromiso con el ambiente. Luego intentaré llegar a las raíces de la actual situación, de manera que no miremos sólo los síntomas sino también las causas más profundas. Así podremos proponer una ecología que, entre sus distintas dimensiones, incorpore el lugar peculiar del ser humano en este mundo y sus relaciones con la realidad que lo rodea. A la luz de esa reflexión quisiera avanzar en algunas líneas amplias de diálogo y de acción que involucren tanto a cada uno de nosotros como a la política internacional. Finalmente, puesto que estoy convencido de que todo cambio necesita motivaciones y un camino educativo, propondré algunas líneas de maduración humana inspiradas en el tesoro de la experiencia espiritual cristiana.

Señala a continuación algunos ejes que atraviesan toda la encíclica (16):

- la íntima relación entre los pobres y la fragilidad del planeta,

- la convicción de que en el mundo todo está conectado,

- la crítica al nuevo paradigma y a las formas de poder que derivan de la tecnología,

- la invitación a buscar otros modos de entender la economía y el progreso,

- el valor propio de cada criatura,

- el sentido humano de la ecología,

- la necesidad de realizar debates sinceros y honestos,

- la grave responsabilidad de la política internacional y local,

- la cultura del descarte y la propuesta de un nuevo estilo de vida.

Temas todos estos que no se cierran ni abandonan, sino que son constantemente replanteados y enriquecidos, y que constituyen parte del acervo sustantivo del pensamiento ambiental latinoamericano.

El primer capítulo titulado "Lo que le está pasando a nuestra casa" realiza una revisión de diversos problemas.

En relación al calentamiento global y la contaminación establece la relación entre la contaminación, la basura y la cultura del descarte. Identifica asimismo 
algunas de las principales formas de contaminación que afectan cotidianamente a las personas y también la contaminación producida por los residuos, incluyendo los desechos peligrosos presentes en distintos ambientes, afirmando que,

Se producen cientos de millones de toneladas de residuos por año, muchos de ellos no biodegradables: residuos domiciliarios y comerciales, residuos de demolición, residuos clínicos, electrónicos e industriales, residuos altamente tóxicos y radioactivos. La tierra, nuestra casa, parece convertirse cada vez más en un inmenso depósito de porquería. En muchos lugares del planeta, los ancianos añoran los paisajes de otros tiempos, que ahora se ven inundados de basura. Tanto los residuos industriales como los productos químicos utilizados en las ciudades y en el agro pueden producir un efecto de bioacumulación en los organismos de los pobladores de zonas cercanas, que ocurre aun cuando el nivel de presencia de un elemento tóxico en un lugar sea bajo. Muchas veces se toman medidas sólo cuando se han producido efectos irreversibles para la salud de las personas. (21)

Emite allí un juicio bastante radical al sostener que: "La tecnología que, ligada a las finanzas, pretende ser la única solución de los problemas, de hecho suele ser incapaz de ver el misterio de las múltiples relaciones que existen entre las cosas, y por eso a veces resuelve un problema creando otros." (20)

Y en una aproximación muy parecida a los planteos de la biomimesis, propuesta tanto en los trabajos de Jorge Riechmann como de Víctor Toledo, afirma que;

Estos problemas están íntimamente ligados a la cultura del descarte, que afecta tanto a los seres humanos excluidos como a las cosas que rápidamente se convierten en basura. Advirtamos, por ejemplo, que la mayor parte del papel que se produce se desperdicia y no se recicla. Nos cuesta reconocer que el funcionamiento de los ecosistemas naturales es ejemplar: las plantas sintetizan nutrientes que alimentan a los herbívoros; estos a su vez alimentan a los seres carnívoros, que proporcionan importantes cantidades de residuos orgánicos, los cuales dan lugar a una nueva generación de vegetales. En cambio, el sistema industrial, al final del ciclo de producción y de consumo, no ha desarrollado la capacidad de absorber y reutilizar residuos y desechos. Todavía no se ha logrado adoptar un modelo circular de producción que asegure recursos para todos y para las generaciones futuras, y que supone limitar al máximo el uso de los recursos no renovables, moderar el consumo, maximizar la eficiencia del aprovechamiento, reutilizar y reciclar. Abordar esta cuestión sería un modo de contrarrestar la cultura del descarte, que termina afectando al planeta entero, pero observamos que los avances en este sentido son todavía muy escasos. (22)

A continuación realiza un planteo doctrinal que confronta muchas de las afirmaciones de la economía ambiental al señalar el clima como un bien común (2326), abordando temas como: la cuestión del agua (27-31); la pérdida de biodiversidad (32-42); el deterioro de la calidad de la vida humana y la decadencia social (43-47); la inequidad planetaria (48-52); denunciando la debilidad de las reacciones (53-59) frente a estos problemas con afirmaciones tan tajantes y duras como:

[...] los poderes económicos continúan justificando el actual sistema mundial, donde priman una especulación y una búsqueda de la renta financiera que tienden a ignorar todo contexto y los efectos sobre la dignidad humana y el medio ambiente. Así se manifiesta que la degradación ambiental y la degradación humana y ética están íntimamente unidas. Muchos dirán que no tienen conciencia de realizar acciones inmorales, porque la distracción constante nos quita la valentía de advertir la realidad de un mundo limitado y finito. Por eso, hoy "cualquier cosa que sea frágil, como el medio ambiente, queda indefensa ante los intereses del mercado divinizado, convertidos en regla absoluta" [33].

Hace aquí referencia a la Exhortación Apostólica ${ }^{4}$ Evangelii gaudium ${ }^{5}$, en la cual ya había señalado su

\footnotetext{
${ }^{4}$ Una Exhortación Apostólica es un tipo de documento dirigido especialmente a los integrantes de la comunidad eclesial, léase a los obispos, presbíteros y diáconos, personas consagradas y a los fieles laicos. A diferencia de una Encíclica que es un documento que tiene un carácter más convocante, como en este caso: "En esta encíclica, intento especialmente entrar en diálogo con todos acerca de nuestra casa común."

${ }^{5}$ Disponible en: $<$ http://w2.vatican.va/content/francesco/es/apost_exhortations/documents/papa-francesco_esortazione-ap_20131124_evangelii-gaudium.html>.
} 
rechazo a lo que considera una economía de exclusión, como se aprecia en la cita siguiente:

\section{No a una economía de la exclusión}

53. Así como el mandamiento de "no matar" pone un límite claro para asegurar el valor de la vida humana, hoy tenemos que decir "no a una economía de la exclusión y la inequidad". Esa economía mata. No puede ser que no sea noticia que muere de frío un anciano en situación de calle y que sí lo sea una caída de dos puntos en la bolsa. Eso es exclusión. No se puede tolerar más que se tire comida cuando hay gente que pasa hambre. Eso es inequidad. Hoy todo entra dentro del juego de la competitividad y de la ley del más fuerte, donde el poderoso se come al más débil. Como consecuencia de esta situación, grandes masas de la población se ven excluidas y marginadas: sin trabajo, sin horizontes, sin salida. Se considera al ser humano en sí mismo como un bien de consumo, que se puede usar y luego tirar. Hemos dado inicio a la cultura del "descarte" que, además, se promueve. Ya no se trata simplemente del fenómeno de la explotación y de la opresión, sino de algo nuevo: con la exclusión queda afectada en su misma raíz la pertenencia a la sociedad en la que se vive, pues ya no se está en ella abajo, en la periferia, o sin poder, sino que se está fuera. Los excluidos no son "explotados" sino desechos, "sobrantes".

54. En este contexto, algunos todavía defienden las teorías del "derrame", que suponen que todo crecimiento económico, favorecido por la libertad de mercado, logra provocar por sí mismo mayor equidad e inclusión social en el mundo. Esta opinión, que jamás ha sido confirmada por los hechos, expresa una confianza burda e ingenua en la bondad de quienes detentan el poder económico y en los mecanismos sacralizados del sistema económico imperante. Mientras tanto, los excluidos siguen esperando. Para poder sostener un estilo de vida que excluye a otros, o para poder entusiasmarse con ese ideal egoísta, se ha desarrollado una globalización de la indiferencia. Casi sin advertirlo, nos volvemos incapaces de compadecernos ante los clamores de los otros, ya no lloramos ante el drama de los demás ni nos interesa cuidarlos, como si todo fuera una responsabilidad ajena que no nos incumbe. La cultura del bienestar nos anestesia y perdemos la calma si el mercado ofrece algo que todavía no hemos comprado, mientras todas esas vidas truncadas por falta de posibilidades nos parecen un mero espectáculo que de ninguna manera nos altera." (2013)
No obstante que reconoce la existencia de una diversidad de opiniones (60-61) respecto a cómo abordar los problemas planteados, esboza criterios para abordarlos muy distantes de los preconizados por la institucionalidad hegemónica.

En el segundo capítulo titulado El Evangelio de la Creación, Francisco busca hacer frente a los problemas ilustrados en el capítulo anterior, mediante una selección de relatos bíblicos, que ofrece una visión completa que proviene de la tradición judeo-cristiana y articula la "enorme responsabilidad" (90) de la humanidad para la creación, la íntima conexión entre todas las criaturas y el hecho de que "el medio ambiente natural es un bien colectivo, patrimonio de toda la humanidad y la responsabilidad de todos" (95). En la Biblia, "el Dios que libera y salva es el mismo Dios que creó el universo, y estos dos caminos divinos de la actuación están conectados íntima e inseparablemente" (73). La historia de la creación es fundamental para la reflexión sobre la relación entre los seres humanos y otras criaturas y sobre cómo el pecado rompe el equilibrio de toda la creación en su totalidad (66). Para esto, incluso... Si es verdad que algunas veces los cristianos hemos interpretado incorrectamente las Escrituras, hoy debemos rechazar con fuerza que, del hecho de ser creados a imagen de Dios y del mandato de dominar la tierra, se deduzca un dominio absoluto sobre las demás criaturas. Es importante leer los textos bíblicos en su contexto, con una hermenéutica adecuada, y recordar que nos invitan a "labrar y cuidar" el jardín del mundo (cf. Gn 2,15). (67), teniendo presente que "el fin último de las demás criaturas no somos nosotros. Pero todas avanzan, junto con nosotros y a través de nosotros, hacia el término común, que es Dios” (83) “[...] siendo creados por el mismo Padre, todos los seres del universo estamos unidos por lazos invisibles y conformamos una especie de familia universal, una sublime comunión que nos mueve a un respeto sagrado, cariñoso y humilde" (89). "Esto no significa igualar a todos los seres vivos y quitarle al ser humano ese valor peculiar que implica al mismo tiempo una tremenda responsabilidad. Tampoco supone una divinización de la tierra que nos privaría del llamado a colaborar con ella y a proteger su fragilidad. Estas concepciones terminarían creando nuevos desequilibrios por escapar de la realidad que nos interpela. A veces se advierte una obsesión por negar toda 
preeminencia a la persona humana, y se lleva adelante una lucha por otras especies que no desarrollamos para defender la igual dignidad entre los seres humanos. Es verdad que debe preocuparnos que otros seres vivos no sean tratados irresponsablemente. Pero especialmente deberían exasperarnos las enormes inequidades que existen entre nosotros, porque seguimos tolerando que unos se consideren más dignos que otros. Dejamos de advertir que algunos se arrastran en una degradante miseria, sin posibilidades reales de superación, mientras otros ni siquiera saben qué hacer con lo que poseen, ostentan vanidosamente una supuesta superioridad y dejan tras de sí un nivel de desperdicio que sería imposible generalizar sin destrozar el planeta. Seguimos admitiendo en la práctica que unos se sientan más humanos que otros, como si hubieran nacido con mayores derechos." (90) "No puede ser real un sentimiento de íntima unión con los demás seres de la naturaleza si al mismo tiempo en el corazón no hay ternura, compasión y preocupación por los seres humanos... Esto pone en riesgo el sentido de la lucha por el ambiente." (91) "Por otra parte, cuando el corazón está auténticamente abierto a una comunión universal, nada ni nadie está excluido de esa fraternidad. Por consiguiente, también es verdad que la indiferencia o la crueldad ante las demás criaturas de este mundo siempre terminan trasladándose de algún modo al trato que damos a otros seres humanos. El corazón es uno solo, y la misma miseria que lleva a maltratar a un animal no tarda en manifestarse en la relación con las demás personas..." (92)

El tercer capítulo se titula Las raíces humanas de la crisis ecológica y presenta un análisis de la situación actual, "a fin de tener en cuenta no sólo sus síntomas, sino también sus causas más profundas" (15), en un diálogo con la filosofía y las ciencias humanas. Las reflexiones sobre la tecnología son un foco inicial del capítulo. Se reconoce la gran contribución de las tecnologías a la mejora de las condiciones de vida, sin embargo, le proporciona a "los que tienen el conocimiento, y sobre todo los recursos económicos para utilizarlas, un dominio impresionante sobre el conjunto de la humanidad y el mundo entero" (104). Es precisamente la mentalidad de dominación tecnocrática que conduce a la destrucción de la naturaleza y la explotación de las personas, especialmente a las poblaciones más vulnerables. "El paradigma tecnocrático también tiende a dominar la economía y la vida política" (109), lo cual nos impide reconocer que "por sí mismo el mercado no puede garantizar el desarrollo humano integral y la inclusión social." (109)

"La modernidad ha estado marcada por un antropocentrismo excesivo" (116): los seres humanos ya no reconocen su lugar correcto en relación con el mundo y asumen una posición egoísta, centrado exclusivamente en ellos mismos y en su propio poder. Esto se traduce en una lógica de "usar y tirar" que justifica todo tipo de residuos, ambiental o humano, que trata tanto de la otra y la naturaleza como objetos simples y da lugar a una gran variedad de formas de dominación. Es esta mentalidad que lleva a la explotación de los niños, el abandono de los ancianos, obligando a los demás a la esclavitud, la práctica de la trata de personas y tirar los bebés por nacer porque no corresponden a lo que quieren los padres, de la venta de "diamantes de sangre" y las pieles de animales en peligro de extinción, y de un exceso de la evaluación de la capacidad del mercado para autorregularse. Esta es también la mentalidad de las muchas mafias dedicadas al tráfico de drogas y el tráfico de órganos (123).

En este sentido, la encíclica aborda dos problemas cruciales del mundo de hoy. Por encima de todo el trabajo: "En cualquier aproximación a una ecología integral, que por definición no excluye los seres humanos, hay que tener en cuenta el valor del trabajo" (124). El trabajo debería ser el ámbito de este múltiple desarrollo personal, donde se ponen en juego muchas dimensiones de la vida: la creatividad, la proyección del futuro, el desarrollo de capacidades, el ejercicio de los valores, la comunicación con los demás, una actitud de adoración. Por eso, en la actual realidad social mundial, más allá de los intereses limitados de las empresas y de una cuestionable racionalidad económica, es necesario que "se siga buscando como prioridad el objetivo del acceso al trabajo por parte de todos" (127), ya que "dejar de invertir en la gente, con el fin de obtener una mayor corto término de ganancia financiera, es un mal negocio para la sociedad" (128).

El segundo problema se refiere a las limitaciones del progreso científico, con clara referencia a los organismos genéticamente modificados (OGM) (132-136). "Es una cuestión ambiental de carácter complejo, por lo cual su tratamiento exige una mirada integral de 
todos sus aspectos, y esto requeriría al menos un mayor esfuerzo para financiar diversas líneas de investigación libre e interdisciplinaria que puedan aportar nueva luz. Se trata de una "cuestión ambiental compleja'." (135) "Si bien no hay comprobación contundente acerca del daño que podrían causar los cereales transgénicos a los seres humanos, y en algunas regiones su utilización ha provocado un crecimiento económico que ayudó a resolver problemas, hay dificultades importantes que no deben ser relativizadas. En muchos lugares, tras la introducción de estos cultivos, se constata una concentración de tierras productivas en manos de pocos debido a "la progresiva desaparición de pequeños productores que, como consecuencia de la pérdida de las tierras explotadas, se han visto obligados a retirarse de la producción directa". Los más frágiles se convierten en trabajadores precarios, y muchos empleados rurales terminan migrando a miserables asentamientos de las ciudades. La expansión de la frontera de estos cultivos arrasa con el complejo entramado de los ecosistemas, disminuye la diversidad productiva y afecta el presente y el futuro de las economías regionales. En varios países se advierte una tendencia al desarrollo de oligopolios en la producción de granos y de otros productos necesarios para su cultivo, y la dependencia se agrava si se piensa en la producción de granos estériles que terminaría obligando a los campesinos a comprarlos a las empresas productoras." (134) "De ese modo, cuando la técnica desconoce los grandes principios éticos, termina considerando legítima cualquier práctica. Como vimos en este capítulo, la técnica separada de la ética difícilmente será capaz de autolimitar su poder." (136)

El cuarto capítulo se titula Ecología Integral y apunta al corazón de las propuestas de la Encíclica, la ecología integral como un nuevo paradigma de la justicia, una ecología "que respete nuestro lugar único como los seres humanos en este mundo y nuestra relación con nuestro entorno." (15) "Cuando se habla de "medio ambiente", se indica particularmente una relación, la que existe entre la naturaleza y la sociedad que la habita. Esto nos impide entender la naturaleza como algo separado de nosotros o como un mero marco de nuestra vida. Estamos incluidos en ella, somos parte de ella y estamos interpenetrados. Las razones por las cuales un lugar se contamina exigen un análisis del funcionamiento de la sociedad, de su economía, de su comportamiento, de sus maneras de entender la realidad. Dada la magnitud de los cambios, ya no es posible encontrar una respuesta específica e independiente para cada parte del problema. Es fundamental buscar soluciones integrales que consideren las interacciones de los sistemas naturales entre sí y con los sistemas sociales."(139) "Por otra parte, el crecimiento económico tiende a producir automatismos y a homogeneizar, en orden a simplificar procedimientos y a reducir costos. Por eso es necesaria una ecología económica, capaz de obligar a considerar la realidad de manera más amplia. Porque "la protección del medio ambiente deberá constituir parte integrante del proceso de desarrollo y no podrá considerarse en forma aislada". Pero al mismo tiempo se vuelve actual la necesidad imperiosa del humanismo, que de por sí convoca a los distintos saberes, también al económico, hacia una mirada más integral e integradora. Hoy el análisis de los problemas ambientales es inseparable del análisis de los contextos humanos, familiares, laborales, urbanos, y de la relación de cada persona consigo misma, que genera un determinado modo de relacionarse con los demás y con el ambiente. Hay una interacción entre los ecosistemas y entre los diversos mundos de referencia social, y así se muestra una vez más que 'el todo es superior a la parte'." (141) "Si todo está relacionado, también la salud de las instituciones de una sociedad tiene consecuencias en el ambiente y en la calidad de vida humana: "Cualquier menoscabo de la solidaridad y del civismo produce daños ambientales". En ese sentido, la ecología social es necesariamente institucional, y alcanza progresivamente las distintas dimensiones que van desde el grupo social primario, la familia, pasando por la comunidad local y la nación, hasta la vida internacional. Dentro de cada uno de los niveles sociales y entre ellos, se desarrollan las instituciones que regulan las relaciones humanas. Todo lo que las dañe entraña efectos nocivos, como la perdida de la libertad, la injusticia y la violencia." (142) "La ecología integral es inseparable de la noción de bien común, un principio que cumple un rol central y unificador en la ética social." (156), pero entendido de una manera concreta: "En las condiciones actuales de la sociedad mundial, donde hay tantas inequidades y cada vez son más las personas descartables, privadas de derechos humanos básicos, el principio del bien común 
se convierte inmediatamente, como lógica e ineludible consecuencia, en un llamado a la solidaridad y en una opción preferencial por los más pobres. Esta opción implica sacar las consecuencias del destino común de los bienes de la tierra, pero, como he intentado expresar en la Exhortación apostólica Evangelii gaudium, exige contemplar ante todo la inmensa dignidad del pobre a la luz de las más hondas convicciones creyentes. Basta mirar la realidad para entender que esta opción hoy es una exigencia ética fundamental para la realización efectiva del bien común." (158) "La noción de bien común incorpora también a las generaciones futuras. Las crisis económicas internacionales han mostrado con crudeza los efectos dañinos que trae aparejado el desconocimiento de un destino común, del cual no pueden ser excluidos quienes vienen detrás de nosotros. Ya no puede hablarse de desarrollo sostenible sin una solidaridad intergeneracional. Cuando pensamos en la situación en que se deja el planeta a las generaciones futuras, entramos en otra lógica, la del don gratuito que recibimos y comunicamos. Si la tierra nos es donada, ya no podemos pensar sólo desde un criterio utilitarista de eficiencia y productividad para el beneficio individual. No estamos hablando de una actitud opcional, sino de una cuestión básica de justicia, ya que la tierra que recibimos pertenece también a los que vendrán.” (159) “¿Qué tipo de mundo queremos dejar a quienes nos sucedan, a los niños que están creciendo? Esta pregunta no afecta sólo al ambiente de manera aislada, porque no se puede plantear la cuestión de modo fragmentario... Se requiere advertir que lo que está en juego es nuestra propia dignidad. Somos nosotros los primeros interesados en dejar un planeta habitable para la humanidad que nos sucederá. Es un drama para nosotros mismos, porque esto pone en crisis el sentido del propio paso por esta tierra." (160) "Las predicciones catastróficas ya no pueden ser miradas con desprecio e ironía. A las próximas generaciones podríamos dejarles demasiados escombros, desiertos y suciedad. El ritmo de consumo, de desperdicio y de alteración del medio ambiente ha superado las posibilidades del planeta, de tal manera que el estilo de vida actual, por ser insostenible, sólo puede terminar en catástrofes, como de hecho ya está ocurriendo periódicamente en diversas regiones."(161) "No imaginemos solamente a los pobres del futuro, basta que recordemos a los pobres de hoy, que tienen pocos años de vida en esta tierra y no pueden seguir esperando. Por eso, 'además de la leal solidaridad intergeneracional, se ha de reiterar la urgente necesidad moral de una renovada solidaridad intrageneracional'." (162) Esta es también la mejor manera de dejar un mundo sostenible para las generaciones futuras, no sólo al proclamar estas verdades, sino también comprometiéndose a cuidar de los pobres de hoy.

El capítulo cinco está titulado Líneas de enfoque y la acción y se aborda la cuestión de lo que podemos y debemos hacer. Los análisis no son suficientes. Necesitamos propuestas "para el diálogo y la acción que involucren tanto a cada uno de nosotros como a la política internacional" (15) e intentar "delinear grandes caminos de diálogo que nos ayuden a salir de la espiral de autodestrucción en la que nos estamos sumergiendo." (163) Para Francisco es un imperativo que las propuestas prácticas no sean desarrolladas de una manera ideológica, superficial o reduccionista... "es indispensable un consenso mundial que lleve, por ejemplo, a programar una agricultura sostenible y diversificada, a desarrollar formas renovables y poco contaminantes de energía, a fomentar una mayor eficiencia energética, a promover una gestión más adecuada de los recursos forestales y marinos, a asegurar a todos el acceso al agua potable" (164), con "adecuados mecanismos de control, de revisión periódica y de sanción de los incumplimientos." (167) "Sigue siendo cierto que hay responsabilidades comunes pero diferenciadas, sencillamente porque, como han dicho los Obispos de Bolivia, 'los países que se han beneficiado por un alto grado de industrialización, a costa de una enorme emisión de gases invernaderos, tienen mayor responsabilidad en aportar a la solución de los problemas que han causado'.” (170)

Para ello, el diálogo es esencial, un término presente en el título de cada sección de este capítulo. "Hay discusiones sobre cuestiones relacionadas con el ambiente donde es difícil alcanzar consensos... la Iglesia no pretende definir las cuestiones científicas ni sustituir a la política, pero invito a un debate honesto y transparente, para que las necesidades particulares o las ideologías no afecten al bien común.” (188)

Sobre esta base, Francisco no tiene miedo de juzgar la dinámica internacional severamente: las Cumbres mundiales sobre el ambiente de los últimos años no res- 
pondieron a las expectativas porque, por falta de decisión política, no alcanzaron acuerdos ambientales globales realmente significativos y eficaces.” (166). Y se pregunta: “Para qué se quiere preservar hoy un poder que será recordado por su incapacidad de intervenir cuando era urgente y necesario hacerlo?" (57). En cambio, lo que se necesita, como los Papas lo han repetido varias veces a partir de la Pacem in Terris, son formas e instrumentos para la gobernanza mundial (175): "un acuerdo sobre los regímenes de gobernanza para toda la gama de los llamados 'bienes comunes globales'." (174), ya que citando (el Compendio de la Doctrina Social de la Iglesia), "hay que recordar que 'la protección ambiental no puede asegurarse sólo en base al cálculo financiero de costos y beneficios. El ambiente es uno de esos bienes que los mecanismos del mercado no son capaces de defender o de promover adecuadamente'." (190) En este quinto capítulo, Francisco insiste en el desarrollo de los procesos decisorios honestas y transparentes, con el fin de "discernir" qué políticas e iniciativas de negocios puede dar lugar a "un auténtico desarrollo integral" (185). En particular, incorpora la idea ir de aguas arriba pues señala que, "un estudio del impacto ambiental no debería ser posterior a la elaboración de un proyecto productivo o de cualquier política, plan o programa a desarrollarse. Tiene que insertarse desde el principio y elaborarse de modo interdisciplinario, transparente e independiente de toda presión económica o política." (183) Plantea asimismo la necesidad de diálogo y transparencia en los procesos decisionales, pues: "La previsión del impacto ambiental de los emprendimientos y proyectos requiere procesos políticos transparentes y sujetos al diálogo, mientras la corrupción, que esconde el verdadero impacto ambiental de un proyecto a cambio de favores, suele llevar a acuerdos espurios que evitan informar y debatir ampliamente." (182) Hace un llamado a los tomadores de decisiones, señalando que: "Es indispensable la continuidad, porque no se pueden modificar las políticas relacionadas con el cambio climático y la protección del ambiente cada vez que cambia un gobierno. Los resultados requieren mucho tiempo, y suponen costos inmediatos con efectos que no podrán ser mostrados dentro del actual período de gobierno. Por eso, sin la presión de la población y de las instituciones siempre habrá resistencia a intervenir, más aún cuando haya urgencias que resolver. Que un político asuma estas responsabilidades con los costos que implican, no responde a la lógica eficientista e inmediatista de la economía y de la política actual, pero si se atreve a hacerlo, volverá a reconocer la dignidad que Dios le ha dado como humano y dejará tras su paso por esta historia un testimonio de generosa responsabilidad. Hay que conceder un lugar preponderante a una sana política, capaz de reformar las instituciones, coordinarlas y dotarlas de mejores prácticas, que permitan superar presiones e inercias viciosas." (181)

El sexto capítulo se titula La educación ecológica y la espiritualidad y se invita a todos a una conversión ecológica, a una toma de conciencia de nuestra origen común, de una pertenencia mutua y de un futuro compartido por todos. Conciencia básica que permita el desarrollo de nuevas convicciones, actitudes y formas de vida. Se destaca así un gran desafío cultural, espiritual y educativo que supondrá largos procesos de regeneración. Las raíces de la crisis cultural son profundas, y no es fácil de remodelar los hábitos y comportamientos. La educación y la formación son los principales desafíos. El punto de partida es "Apostar por otro estilo de vida". "Dado que el mercado tiende a crear un mecanismo consumista compulsivo para colocar sus productos, las personas terminan sumergidas en la vorágine de las compras y los gastos innecesarios. El consumismo obsesivo es el reflejo subjetivo del paradigma tecnoeconómico." Ocurre lo que ya señalaba Romano Guardini: el ser humano "acepta los objetos y las formas de vida, tal como le son impuestos por la planificación y por los productos fabricados en serie y, después de todo, actúa así con el sentimiento de que eso es lo racional y lo acertado". Tal paradigma hace creer a todos que son libres mientras tengan una supuesta libertad para consumir, cuando quienes en realidad poseen la libertad son los que integran la minoría que detenta el poder económico y financiero. En esta confusión, la humanidad posmoderna no encontró una nueva comprensión de sí misma que pueda orientarla, y esta falta de identidad se vive con angustia. Tenemos demasiados medios para unos escasos y raquíticos fines." (203) "La situación actual del mundo "provoca una sensación de inestabilidad e inseguridad que a su vez favorece formas de egoísmo colectivo". Cuando las personas se vuelven autorreferenciales y se aíslan en su propia conciencia, 
acrecientan su voracidad. Mientras más vacío está el corazón de la persona, más necesita objetos para comprar, poseer y consumir. En este contexto, no parece posible que alguien acepte que la realidad le marque límites. Tampoco existe en ese horizonte un verdadero bien común. Si tal tipo de sujeto es el que tiende a predominar en una sociedad, las normas sólo serán respetadas en la medida en que no contradigan las propias necesidades. Por eso, no pensemos sólo en la posibilidad de terribles fenómenos climáticos o en grandes desastres naturales, sino también en catástrofes derivadas de crisis sociales, porque la obsesión por un estilo de vida consumista, sobre todo cuando sólo unos pocos puedan sostenerlo, sólo podrá provocar violencia y destrucción recíproca." (204) "Sin embargo, no todo está perdido, porque los seres humanos, capaces de degradarse hasta el extremo, también pueden sobreponerse, volver a optar por el bien y regenerarse, más allá de todos los condicionamientos mentales y sociales que les impongan... A cada persona de este mundo le pido que no olvide esa dignidad suya que nadie tiene derecho a quitarle." (205) "Un cambio en los estilos de vida podría llegar a ejercer una sana presión sobre los que tienen poder político, económico y social. Es lo que ocurre cuando los movimientos de consumidores logran que dejen de adquirirse ciertos productos y así se vuelven efectivos para modificar el comportamiento de las empresas, forzándolas a considerar el impacto ambiental y los patrones de producción... Ello nos recuerda la responsabilidad social de los consumidores. "Comprar es siempre un acto moral, y no sólo económico".”(206) “Siempre es posible volver a desarrollar la capacidad de salir de sí hacia el otro. Sin ella no se reconoce a las demás criaturas en su propio valor, no interesa cuidar algo para los demás, no hay capacidad de ponerse límites para evitar el sufrimiento o el deterioro de lo que nos rodea. La actitud básica de auto-trascenderse, rompiendo la conciencia aislada y la auto-referencialidad, es la raíz que hace posible todo cuidado de los demás y del medio ambiente, y que hace brotar la reacción moral de considerar el impacto que provoca cada acción y cada decisión personal fuera de uno mismo. Cuando somos capaces de superar el individualismo, realmente se puede desarrollar un estilo de vida alternativo y se vuelve posible un cambio importante en la sociedad."(208). Pro- pone una Educación para la alianza entre la humanidad y el ambiente, señalando al respecto: "La educación ambiental ha ido ampliando sus objetivos. Si al comienzo estaba muy centrada en la información científica y en la concientización y prevención de riesgos ambientales, ahora tiende a incluir una crítica de los "mitos" de la modernidad basados en la razón instrumental (individualismo, progreso indefinido, competencia, consumismo, mercado sin reglas) y también a recuperar los distintos niveles del equilibrio ecológico: el interno con uno mismo, el solidario con los demás, el natural con todos los seres vivos, el espiritual con Dios. La educación ambiental debería disponernos a dar ese salto hacia el Misterio, desde donde una ética ecológica adquiere su sentido más hondo. Por otra parte, hay educadores capaces de replantear los itinerarios pedagógicos de una ética ecológica, de manera que ayuden efectivamente a crecer en la solidaridad, la responsabilidad y el cuidado basado en la compasión.” (210) Señala que las pequeñas acciones cotidianas de cuidado "derraman un bien en la sociedad que siempre produce frutos más allá de lo que se pueda constatar, porque provocan en el seno de esta tierra un bien que siempre tiende a difundirse, a veces invisiblemente. Además, el desarrollo de estos comportamientos nos devuelve el sentimiento de la propia dignidad, nos lleva a una mayor profundidad vital, nos permite experimentar que vale la pena pasar por este mundo." (212) Y añade que, "Contra la llamada cultura de la muerte, la familia constituye la sede de la cultura de la vida". En la familia se cultivan los primeros hábitos de amor y cuidado de la vida, como por ejemplo el uso correcto de las cosas, el orden y la limpieza, el respeto al ecosistema local y la protección de todos los seres creados. La familia es el lugar de la formación integral, donde se desenvuelven los distintos aspectos, íntimamente relacionados entre sí, de la maduración personal. En la familia se aprende a pedir permiso sin avasallar, a decir "gracias" como expresión de una sentida valoración de las cosas que recibimos, a dominar la agresividad o la voracidad, y a pedir perdón cuando hacemos algún daño. Estos pequeños gestos de sincera cortesía ayudan a construir una cultura de la vida compartida y del respeto a lo que nos rodea. (213) "Al mismo tiempo, si se quiere conseguir cambios profundos, hay que tener presente que los paradigmas de pensa- 
miento realmente influyen en los comportamientos. La educación será ineficaz y sus esfuerzos serán estériles si no procura también difundir un nuevo paradigma acerca del ser humano, la vida, la sociedad y la relación con la naturaleza. De otro modo, seguirá avanzando el paradigma consumista que se transmite por los medios de comunicación y a través de los eficaces engranajes del mercado." (215) Hace un llamado a una conversión ecológica de los cristianos señalando que: "la gran riqueza de la espiritualidad cristiana, generada por veinte siglos de experiencias personales y comunitarias, ofrece un bello aporte al intento de renovar la humanidad. Quiero proponer a los cristianos algunas líneas de espiritualidad ecológica que nacen de las convicciones de nuestra fe, porque lo que el Evangelio nos enseña tiene consecuencias en nuestra forma de pensar, sentir y vivir. No se trata de hablar tanto de ideas, sino sobre todo de las motivaciones que surgen de la espiritualidad para alimentar una pasión por el cuidado del mundo. Porque no será posible comprometerse en cosas grandes sólo con doctrinas sin una mística que nos anime, sin 'unos móviles interiores que impulsan, motivan, alientan y dan sentido a la acción personal y comunitaria'." (216) "Si 'los desiertos exteriores se multiplican en el mundo porque se han extendido los desiertos interiores', la crisis ecológica es un llamado a una profunda conversión interior... algunos cristianos comprometidos y orantes, bajo una excusa de realismo y pragmatismo, suelen burlarse de las preocupaciones por el medio ambiente. Otros son pasivos, no se deciden a cambiar sus hábitos y se vuelven incoherentes. Les hace falta entonces una conversión ecológica, que implica dejar brotar todas las consecuencias de su encuentro con Jesucristo en las relaciones con el mundo que los rodea. Vivir la vocación de ser protectores de la obra de Dios es parte esencial de una existencia virtuosa, no consiste en algo opcional ni en un aspecto secundario de la experiencia cristiana." (217) "Esta conversión supone diversas actitudes que se conjugan para movilizar un cuidado generoso y lleno de ternura. En primer lugar implica gratitud y gratuidad, es decir, un reconocimiento del mundo como un don recibido del amor del Padre, que provoca como consecuencia actitudes gratuitas de renuncia y gestos generosos aunque nadie los vea o los reconozca... También implica la amorosa conciencia de no estar desconectados de las demás criaturas, de formar con los demás seres del universo una preciosa comunión universal. Para el creyente, el mundo no se contempla desde fuera sino desde dentro, reconociendo los lazos con los que el Padre nos ha unido a todos los seres. Además, haciendo crecer las capacidades peculiares que Dios le ha dado, la conversión ecológica lleva al creyente a desarrollar su creatividad y su entusiasmo, para resolver los dramas del mundo... No entiende su superioridad como motivo de gloria personal o de dominio irresponsable, sino como una capacidad diferente, que a su vez le impone una grave responsabilidad que brota de su fe." (220) "Diversas convicciones de nuestra fe, desarrolladas al comienzo de esta Encíclica, ayudan a enriquecer el sentido de esta conversión, como la conciencia de que cada criatura refleja algo de Dios y tiene un mensaje que enseñarnos... También el reconocimiento de que Dios ha creado el mundo inscribiendo en él un orden y un dinamismo que el ser humano no tiene derecho a ignorar." (221) "Por otro lado, ninguna persona puede madurar en una feliz sobriedad si no está en paz consigo mismo. Parte de una adecuada comprensión de la espiritualidad consiste en ampliar lo que entendemos por paz, que es mucho más que la ausencia de guerra. La paz interior de las personas tiene mucho que ver con el cuidado de la ecología y con el bien común, porque, auténticamente vivida, se refleja en un estilo de vida equilibrado unido a una capacidad de admiración que lleva a la profundidad de la vida. La naturaleza está llena de palabras de amor, pero ¿cómo podremos escucharlas en medio del ruido constante, de la distracción permanente y ansiosa, o del culto a la apariencia? Muchas personas experimentan un profundo desequilibrio que las mueve a hacer las cosas a toda velocidad para sentirse ocupadas, en una prisa constante que a su vez las lleva a atropellar todo lo que tienen a su alrededor. Esto tiene un impacto en el modo como se trata al ambiente. Una ecología integral implica dedicar algo de tiempo para recuperar la serena armonía con la creación, para reflexionar acerca de nuestro estilo de vida y nuestros ideales, para contemplar al Creador, que vive entre nosotros y en lo que nos rodea, cuya presencia 'no debe ser fabricada sino descubierta, develada'." (225) "El cuidado de la naturaleza es parte de un estilo de vida que implica capacidad de convivencia y de comunión. Jesús nos recordó que tenemos a Dios 
como nuestro Padre común y que eso nos hace hermanos. El amor fraterno sólo puede ser gratuito, nunca puede ser un pago por lo que otro realice ni un anticipo por lo que esperamos que haga. Por eso es posible amar a los enemigos. Esta misma gratuidad nos lleva a amar y aceptar el viento, el sol o las nubes, aunque no se sometan a nuestro control. Por eso podemos hablar de una fraternidad universal." (228) "Hace falta volver a sentir que nos necesitamos unos a otros, que tenemos una responsabilidad por los demás y por el mundo, que vale la pena ser buenos y honestos. Ya hemos tenido mucho tiempo de degradación moral, burlándonos de la ética, de la bondad, de la fe, de la honestidad, y llegó la hora de advertir que esa alegre superficialidad nos ha servido de poco. Esa destrucción de todo fundamento de la vida social termina enfrentándonos unos con otros para preservar los propios intereses, provoca el surgimiento de nuevas formas de violencia y crueldad e impide el desarrollo de una verdadera cultura del cuidado del ambiente." (229) El amor, lleno de pequeños gestos de cuidado mutuo, es también civil y político, y se manifiesta en todas las acciones que procuran construir un mundo mejor. El amor a la sociedad y el compromiso por el bien común son una forma excelente de la caridad, que no sólo afecta a las relaciones entre los individuos, sino a "las macro-relaciones, como las relaciones sociales, económicas y políticas". Por eso, la Iglesia propuso al mundo el ideal de una "civilización del amor". El amor social es la clave de un auténtico desarrollo: "Para plasmar una sociedad más humana, más digna de la persona, es necesario revalorizar el amor en la vida social -a nivel político, económico, cultural-, haciéndolo la norma constante y suprema de la acción". En este marco, junto con la importancia de los pequeños gestos cotidianos, el amor social nos mueve a pensar en grandes estrategias que detengan eficazmente la degradación ambiental y alienten una cultura del cuidado que impregne toda la sociedad. Cuando alguien reconoce el llamado de Dios a intervenir junto con los demás en estas dinámicas sociales, debe recordar que eso es parte de su espiritualidad, que es ejercicio de la caridad y que de ese modo madura y se santifica." (231)

\section{Francisco ¿herencia o continuidad del pensamiento socioambiental?}

Como lo he señalado antes, los documentos del papa Francisco la Encíclica Laudato si', así como la Exhortación Apostólica Evangelii gaudium, constituyen una excelente noticia y aporte al pensamiento y acción en pro de la sustentabilidad. Si bien ambos documentos son absolutamente coincidentes en la lectura de la realidad del mundo actual. Sus miradas difieren en la radicalidad de la crítica con la cual se diagnostica los problemas que la humanidad enfrenta. El tenor de ambos difiere ya que en un caso, la Exhortación está iniciando un diálogo al interior de la Iglesia Católica y consecuentemente puede argumentar desde una ética de máximos, y en el caso de la Encíclica está haciendo un urgente llamado a salvar el planeta, y es un "reclamo a la humanidad en general, sin importar credo religioso", "para que exijan de sus líderes acciones rápidas para salvar el planeta". Asimismo la Encíclica abre un nuevo capítulo en el diálogo entre la Iglesia y la ciencia. El Papa habla con autoridad religiosa, pero es profundamente respetuoso del aporte de la ciencia. De modo tal que su planteo aquí es desde una ética de mínimos, que hace referencia a las condiciones y comportamientos mínimos de convivencia comunes en los diferentes ámbitos sociales en el mundo. Está formada por elementos básicos en los que todos podemos estar de acuerdo y que posibilitan la convivencia y la tolerancia. Asume entonces una fórmula de pluralismo moral que "consiste en que convivan distintas éticas de máximos, distintas éticas que hacen ofertas de vida feliz, que hacen propuestas de vida buena, que aconsejan distintos proyectos de vida buena, siempre que dialoguen entre sí y puedan compartir por lo menos unos mínimos valores de justicia con los que no se puede vivir sin caer en inhumanidad." (Entrevista a Adela Cortina en Filosofía hoy ${ }^{6}$.

La pregunta que sin embargo surge, al examinar las reacciones de los sectores defensores del modelo existente, es si ¿Será posible que participen de ese compartir mínimos valores de justicia, quienes defienden a rajatabla el modelo hegemónico y ya han descalificado

\footnotetext{
${ }^{6}$ Disponible en: <http://www.filosofiahoy.es/index.php/mod.pags/mem.detalle/relcategoria.5255/idpag.6471/prev.true/chk.7aae09d608497f6 $1 \mathrm{fe} 2 \mathrm{e} 1600 \mathrm{c} 3876 \mathrm{ee} 4 . \mathrm{html}>$.
} 
la Encíclica por su ignorancia de la economía? ${ }^{7}$ Como lo hizo Samuel Gregg del Acton Institute en "Pope Francis and Poverty" refiriéndose a la Exhortación Apostólica Evangelii gaudium,

Mi crítica de ninguna manera pretende dar a entender que todas las observaciones de Francisco sobre la vida económica son ingenuas o simplemente erróneas. Si llega el caso, dice varias cosas que resonarán con los que favorecen a la empresa y los mercados libres.

y en otros artículos: "Laudato Si': Well Intentioned, Economically Flawed" (24.06.15); "Pope Francis and Economic Populism" (29.07.15), donde refiriéndose a la Encíclica señala:

Pero mientras que la mayor parte de las reflexiones del texto sobre cuestiones de política públicas y centran en el medio ambiente, un tema subterráneo que se vuelve decididamente visible de vez en cuando es la visión profundamente negativo de la encíclica respecto de los mercados libres. Esto confirmaría que la reacción de este pontificado, a las respetuosas preguntas planteadas acerca de la idoneidad del análisis económico contenido en la Exhortación apostólica del año 2013 Evangelii Gaudium de Francisco, ha sido simplemente reciclar (sin doble sentido) algunos de los argumentos de este documento, probadamente erróneos en relación a los efectos de la economía de mercado en la naturaleza.

\section{Sostiene también que,}

No obstante, muchos problemas conceptuales y pretensiones empíricas cuestionables caracterizan la visión de la encíclica respecto de la vida económica contemporánea.

\section{Y continúa afirmando que,}

[...] es lamentable que este pontificado parezca tan poco dispuesto a emprender una discusión seria en torno a los méritos morales y económicos de la economía de mercado. Lo tristemente irónico de todo esto es que la misma encíclica que expresa tales afirmaciones tan vagas sobre el libre mercado y sus partidarios también contiene numerosos llamados de bienvenida al debate razonado y amplio $\left(\mathrm{n}^{\circ} 16,61,135,138,165\right)$ sobre la manera en que hemos de abordar los problemas ambientales y económicos. Laudato si' enfatiza, a su vez, que la Iglesia no tiene el monopolio de la sabiduría sobre la dimensión prudencial de las cuestiones ambientales y económicas. Pero el uso en la encíclica de frases tales como "mercado divinizado" ( $\left.\mathrm{n}^{\mathrm{o}} 56\right)$ y "concepción mágica del mercado" ( $\left.\mathrm{n}^{\circ} 190\right)$; la asociación que hace del relativismo moral con la "mano invisible" de Adam Smith ( $\left.\mathrm{n}^{\circ} 123\right)$; su implacable vinculación del mercado con el materialismo y el consumismo (que no han tenido dificultad para florecer en las economías que no son de mercado); su falta de crítica a los regímenes populistas de izquierda que han generado destrucción económica y aumentado la pobreza en países tales como la Argentina y Venezuela; y su atribución de motivos sospechosos a quienes favorecen los mercados, son contrarios a este llamado al debate abierto y respetuoso."

Queda claro de la lectura anterior que existen escasas coincidencias entre quienes defienden el libre operar de los mercados y el pensamiento en la Encíclica papal, algo que se hace más evidente aún al leer un artículo recientemente publicado en The Guardian ${ }^{9}$,

\footnotetext{
7 "My critique is by no means intended to imply that all of Pope Francis's observations about economic life are naïve or simply mistaken. As it happens, he says several things that will resonate with those who favor free enterprise and markets." En: <http://www.nationalreview.com/ corner/365004/pope-francis-and-poverty-samuel-gregg $>$.

8 "But while most of the text's reflections upon public policy issues focus on the environment, a subterranean theme that becomes decidedly visible from time-to-time is the encyclical's deeply negative view of free markets. This would confirm that this pontificate's reaction to respect full questions asked about the adequacy of the economic analysis contained in Francis's 2013 Apostolic Exhortation Evangelii Gaudium has been to simply recycle (no pun intended) some of that document's demonstrably flawed arguments concerning the market economy's nature and effects." <http://spectator.org/articles/63160/laudato-si\%E2\%80\%99-well-intentioned-economically-flawed>. "Nonetheless, many conceptual problems and questionable empirical claims characterize the encyclical's vision of contemporary economic life." En: < http://www.acton.org/ pub/commentary/2015/06/24/laudato-si $\%$ E2\%80\%99-well-intentioned-economically-flawed $>$.

${ }^{9}$ Versión original disponible en: $<$ http://www.theguardian.com/sustainable-business/2015/jul/21/capitalism-alternatives-sustainable-development-failing?CMP=share_btn_tw $>$.
} 
"Desafíos desde los movimientos de justicia ambiental. La economía verde no salva al capitalismo", de Ashish Kothari, Federico Demaria y Alberto Acosta, en el cual señalan que,

Incluso el Papa Francisco en la 'Encíclica Laudato Si' -al igual que otros líderes religiosos como el Dalai Lama- ha sido explícito en la necesidad de redefinir el progreso: "Para que surjan nuevos modelos de progreso, necesitamos "cambiar el modelo de desarrollo global", [...] No basta conciliar, en un término medio, el cuidado de la naturaleza con la renta financiera, o la preservación del ambiente con el progreso. En este tema los términos medios son sólo una pequeña demora en el derrumbe. Simplemente se trata de redefinir el progreso. [...] muchas veces la calidad real de la vida de las personas disminuye - por el deterioro del ambiente, la baja calidad de los mismos productos alimenticios o el agotamiento de algunos recursos- en el contexto de un crecimiento de la economía. En este marco, el discurso del crecimiento sostenible suele convertirse en un recurso diversivo y exculpatorio que absorbe valores del discurso ecologista dentro de la lógica de las finanzas y de la tecnocracia, y la responsabilidad social y ambiental de las empresas suele reducirse a una serie de acciones de marketing e imagen. Igualmente explicita es la reciente "Declaración islámica sobre el cambio climático global" cuando dice: "Reconocemos la descomposición (fasād) que los humanos han causado en la Tierra debido a nuestra incesante búsqueda del crecimiento económico y el consumo." $(<$ http://rebelion.org/noticia.php?id=202775 $>$ )

Por su parte, Leonardo Boff en un breve artículo en el cual realiza un paralelo entre la encíclica "Sobre el Cuidado de la Casa Común" y la "Carta de la Tierra"10 destaca la mención que hace de ella en uno de los puntos más fundamentales, el 207, que dice:

La Carta de la Tierra ${ }^{11}$ nos invitaba a todos a dejar atrás una etapa de autodestrucción y a comenzar de nuevo, pero todavía no hemos desarrollado una conciencia universal que lo haga posible. Por eso me atrevo a proponer nuevamente aquel precioso desafío: "Como nunca antes en la historia, el destino común nos hace un llamado a buscar un nuevo comienzo [...] Que el nuestro sea un tiempo que se recuerde por el despertar de una nueva reverencia ante la vida; por la firme resolución de alcanzar la sostenibilidad; por el aceleramiento en la lucha por la justicia y la paz y por la alegre celebración de la vida" [148].

Y señala a continuación sus múltiples afinidades comunes,

Tratan del estado degradado de la Tierra y de la vida en sus varias dimensiones, fuera de la visión convencional que se restringe al ambientalismo. Se inscriben dentro del nuevo paradigma relacional y holístico, el único, así nos parece, capaz de darnos todavía esperanza.

En primer lugar aparece el mismo espíritu que atraviesa los textos: de forma analítica, recogiendo los datos científicos más seguros, de forma crítica, denunciando el actual sistema que produce el desequilibrio de la Tierra, y de forma esperanzadora, apuntando salidas salvadoras. No se rinde a la resignación sino que confía en la capacidad humana de forjar un nuevo estilo de vida y en la acción innovadora del Creador, "soberano amante de la vida" (Sab 11,26).

Hay un mismo punto de partida. Dice la Carta: "Los patrones dominantes de producción y consumo están causando devastación ambiental, agotamiento de recursos y una extinción masiva de especies" (Preámbulo, 2). Repite la encíclica: "basta mirar la realidad con sinceridad para ver que hay un gran deterioro de nuestra casa común... el actual sistema mundial es insostenible desde diversos puntos de vista" (n. 61).

Hay la misma propuesta. Afirma la Carta: "Se necesitan cambios fundamentales en nuestros valores, instituciones y formas de vida" (Preámbulo, 3). La encíclica enfatiza: "Toda pretensión de cuidar y mejorar el mundo supone cambios profundos en los estilos de vida, los modelos de producción y de consumo, las estructuras consolidadas de poder que rigen hoy la sociedad" (n. 5). Una gran novedad, propia del nuevo paradigma cosmológico y ecológico, es esta afirmación de la Carta: "Nuestros retos ambientales, económicos, políticos, sociales y espirituales, están interrelacionados y juntos podemos forjar soluciones incluyentes" (Preámbulo,

\footnotetext{
${ }^{10}$ Disponible en: $<$ http://www.servicioskoinonia.org/boff/articulo.php?num=720>.

${ }^{11}$ Disponible en: <http://www.earthcharterchina.org/esp/text.html $>$.
} 
3). Hay un eco de esta afirmación en la encíclica: "hay algunos ejes que atraviesan toda la encíclica: la íntima relación entre los pobres y la fragilidad del planeta, la convicción de que en el mundo todo está conectado, la invitación a buscar otros modos de entender la economía y el progreso, el valor propio de cada criatura, el sentido humano de la ecología y la propuesta de un nuevo estilo de vida" (n. 16). Aquí toma valor la solidaridad entre todos, la sobriedad compartida y "pasar de la avidez a la generosidad y a saber compartir" (n. 9).

La Carta afirma que "hay un espíritu de parentesco con toda la vida" (Preámbulo 4). Lo mismo afirma la encíclica: "Todo está relacionado, y todos los seres humanos estamos juntos como hermanos y hermanas... y nos unimos también, con tierno cariño, al hermano sol, a la hermana luna, al hermano río y a la Madre Tierra" (n. 92). Es la franciscana fraternidad universal.

La Carta De la Tierra enfatiza que es nuestro deber "respetar y cuidar de la comunidad de vida... respetar la Tierra en toda su diversidad" (I, 1). Toda la encíclica, comenzando por el título "cuidar de la Casa Común" hace de ese imperativo una especie de ritornelo. Propone "alimentar una pasión por el cuidado de mundo" (n. 216) y "una cultura del cuidado que impregne toda la sociedad" (n. 231). Aquí surge el cuidado no como mera benevolencia puntual sino como un nuevo paradigma, amoroso y amigo de la vida y de todo lo que existe y vive. Otra afinidad importante es el valor asignado a la justicia social. La Carta mantiene una fuerte relación entre ecología y "la justicia social y económica" que "protege a los vulnerables y sirve a aquellos que sufren" (n. III, 9 c). La encíclica alcanza uno de sus puntos altos al afirmar "que un verdadero planteo ecológico debe integrar la justicia para oír tanto el grito de la Tierra como el grito de los pobres" (n. 49; 53).

Tanto la Carta de la Tierra como la encíclica subrayan contra el sentido común vigente que "cada forma de vida tiene valor, independientemente de su uso humano" (I, 1, a). El Papa reafirma que "todas las criaturas están conectadas, cada una debe ser valorada con afecto y admiración, y todos los seres nos necesitamos unos a otros" (n. 42). En nombre de esta comprensión hace una vigorosa crítica al antropocentrismo (nn. 115-120), pues solamente ve la relación del ser humano con la naturaleza usándola y devastándola y no al contrario, olvidando que él forma parte de ella y que su misión es la de ser su guardián y cuidador.

La Carta de la Tierra formuló una definición de paz de las más felices que han sido elaboradas por la reflexión humana: "la plenitud que resulta de las relaciones correctas consigo mismo, con otras personas, con otras culturas, con otras vidas, con la Tierra y con el Todo del cual somos parte" $(16$, f). Si la paz, según el Papa Pablo VI, es "el equilibrio del movimiento" entonces la encíclica dice que el "equilibrio ecológico tiene que ser el interior con uno mismo, el solidario con los demás, el natural con todos los seres vivos, el espiritual con Dios" (n. 210). El resultado de ese proceso es la paz perenne tan ansiada por los pueblos.

Estos dos documentos son faros que nos guían en estos tiempos sombríos, capaces de devolvernos la necesaria esperanza de que todavía podemos salvar la Casa Común y a nosotros mismos.

Hay dos hechos significativos que considero necesario destacar, el primero, es que considero que en la Encíclica existe una referencia indirecta al libro de Leonardo Boff, Ecología: grito de la tierra, grito de los pobres, quien en cuya introducción señala que su propósito con ese libro fue,

[...] interrelacionar el clamor del oprimido con el clamor de la Tierra. El grito del oprimido ha sido objeto de una intensa reflexión fundamentada en prácticas solidarias de liberación. De ellas nació la teología de la liberación. Nunca en la historia del cristianismo se asignó un puesto tan central al pobre, haciéndolo sujeto de su liberación en la medida en que se hace consciente de lo perverso de su situación y se organiza con otros para superarla... (1996, p. 11).

\section{Continúa en el párrafo siguiente afirmando:}

La Tierra también clama. La lógica que explota a las clases y somete a los pueblos a los intereses de unos pocos países ricos y poderosos es la misma que depreda la Tierra y expolia sus riquezas, sin solidaridad para con el resto de la humanidad y las generaciones futuras. (1996, p. 11).

El texto de la Encíclica en su punto 49 refiriéndose a la Inequidad planetaria afirma lo siguiente,

Quisiera advertir que no suele haber conciencia clara de los problemas que afectan particularmente a los 
excluidos. Ellos son la mayor parte del planeta, miles de millones de personas. Hoy están presentes en los debates políticos y económicos internacionales, pero frecuentemente parece que sus problemas se plantean como un apéndice, como una cuestión que se añade casi por obligación o de manera periférica, si es que no se los considera un mero daño colateral. De hecho, a la hora de la actuación concreta, quedan frecuentemente en el último lugar. Ello se debe en parte a que muchos profesionales, formadores de opinión, medios de comunicación y centros de poder están ubicados lejos de ellos, en áreas urbanas aisladas, sin tomar contacto directo con sus problemas. Viven y reflexionan desde la comodidad de un desarrollo y de una calidad de vida que no están al alcance de la mayoría de la población mundial. Esta falta de contacto físico y de encuentro, a veces favorecida por la desintegración de nuestras ciudades, ayuda a cauterizar la conciencia y a ignorar parte de la realidad en análisis sesgados. Esto a veces convive con un discurso "verde". Pero hoy no podemos dejar de reconocer que un verdadero planteo ecológico se convierte siempre en un planteo social, que debe integrar la justicia en las discusiones sobre el ambiente, para escuchar tanto el clamor de la tierra como el clamor de los pobres. (49) (las cursivas provienen del texto original).

El segundo hecho a destacar, es que de modo explícito en este caso se hace una referencia en el punto 149 a Juan Carlos Scannone, S.J. miembro fundador de la Filosofía de la Liberación (FL), movimiento filosófico de finales del sesenta e inicios del setenta del siglo pasado y vinculado al igual que Leonardo Boff a la Teología de la Liberación. La cita es la siguiente:

[117] Algunos autores han mostrado los valores que suelen vivirse, por ejemplo, en las "villas", chabolas o favelas de América Latina: cf. Juan Carlos Scannone, S.J., "La irrupción del pobre y la lógica de la gratuidad", en Juan Carlos Scannone y Marcelo Perine (Eds.), Irrupción del pobre y quehacer filosófico. Hacia una nueva racionalidad. Buenos Aires, 1993.p. 225-230.
Al igual que la comparación hecha por Boff respecto a la Carta de la Tierra y la Encíclica, creo que es posible hacer un paralelo con el "Manifiesto por la Vida. Por una ética para la sustentabilidad"12, documento que resume el esfuerzo realizado para contribuir desde el Pensamiento Ambiental Latinoamericano al cuidado de nuestra casa común.

El Manifiesto por la Vida (MV) se inicia afirmando que la crisis ambiental es una crisis de civilización. Laudato si' (LS) sostiene "la posibilidad de una "catástrofe ecológica bajo el efecto de la explosión de la civilización industrial", subrayando la "urgencia y la necesidad de un cambio radical en el comportamiento de la humanidad", porque "los progresos científicos más extraordinarios, las proezas técnicas más sorprendentes, el crecimiento económico más prodigioso, si no van acompañados por un auténtico progreso social y moral, se vuelven en definitiva contra el hombre"“" (4) Y más adelante señala que no nos encontramos antes dos crisis, una ecológica y otra social, sino una sola crisis.

No hay dos crisis separadas, una ambiental y otra social, sino una sola y compleja crisis socio-ambiental. Las líneas para la solución requieren una aproximación integral para combatir la pobreza, para devolver la dignidad a los excluidos y simultáneamente para cuidar la naturaleza. (139)

En MV se afirma que la crisis ambiental es la crisis de nuestro tiempo. Al respecto LS señala en el punto 161,

\begin{abstract}
Las predicciones catastróficas ya no pueden ser miradas con desprecio e ironía. A las próximas generaciones podríamos dejarles demasiados escombros, desiertos y suciedad. El ritmo de consumo, de desperdicio y de alteración del medio ambiente ha superado las posibilidades del planeta, de tal manera que el estilo de vida actual, por ser insostenible, sólo puede terminar en catástrofes, como de hecho ya está ocurriendo periódicamente en diversas regiones.
\end{abstract}

\footnotetext{
${ }^{12}$ El "Manifiesto por la Vida. Por una ética para la sustentabilidad" fue un documento elaborado como producto del Seminario convocado por el PNUMA a petición del Foro de Ministros del Medio Ambiente de América Latina y el Caribe celebrada en octubre de 2001. Dicho seminario regional realizado en Bogotá sobre "principios éticos y desarrollo sustentable" como aporte a la Cumbre de Desarrollo Sostenible en Johannesburgo dio origen no sólo al Manifiesto sino que además a un libro publicado por el PNUMA y CEPAL, titulado "Etica, vida, sustentabilidad" el cual fue coordinado por Enrique Leff y contiene 23 trabajos presentados por los participantes en el mencionado seminario. Disponible en: $<$ http://www.scielo.br/pdf/asoc/n10/16893.pdf>.
} 


\section{Continua diciendo que,}

La dificultad para tomar en serio este desafío tiene que ver con un deterioro ético y cultural, que acompaña al deterioro ecológico. El hombre y la mujer del mundo posmoderno corren el riesgo permanente de volverse profundamente individualistas, y muchos problemas sociales se relacionan con el inmediatismo egoísta actual, con las crisis de los lazos familiares y sociales, con las dificultades para el reconocimiento del otro. (162)

Y más adelante sostiene la necesidad de un cambio de paradigma, ya que,

Al mismo tiempo, si se quiere conseguir cambios profundos, hay que tener presente que los paradigmas de pensamiento realmente influyen en los comportamientos. La educación será ineficaz y sus esfuerzos serán estériles si no procura también difundir un nuevo paradigma acerca del ser humano, la vida, la sociedad y la relación con la naturaleza. De otro modo, seguirá avanzando el paradigma consumista que se transmite por los medios de comunicación y a través de los eficaces engranajes del mercado. (215)

En relación a la necesidad planteada en el MV de una Ética de una producción para la vida, en la Encíclica se afirma que,

La política no debe someterse a la economía y ésta no debe someterse a los dictámenes y al paradigma eficientista de la tecnocracia. Hoy, pensando en el bien común, necesitamos imperiosamente que la política y la economía, en diálogo, se coloquen decididamente al servicio de la vida, especialmente de la vida humana. (189)

El MV demanda una Ética del conocimiento y diálogo de saberes, al respecto en LS se señala,

No se puede sostener que las ciencias empíricas explican completamente la vida, el entramado de todas las criaturas y el conjunto de la realidad. Eso sería sobrepasar indebidamente sus confines metodológicos limitados. Si se reflexiona con ese marco cerrado, desaparecen la sensibilidad estética, la poesía, y aun la capacidad de la razón para percibir el sentido y la finalidad de las cosas. [...] En realidad, es ingenuo pensar que los principios éticos puedan presentarse de un modo puramente abstracto, desligados de todo contexto, y el hecho de que aparezcan con un lenguaje religioso no les quita valor alguno en el debate público. Los principios éticos que la razón es capaz de percibir pueden reaparecer siempre bajo distintos ropajes y expresados con lenguajes diversos, incluso religiosos. (199)

Por otra parte, cualquier solución técnica que pretendan aportar las ciencias será impotente para resolver los graves problemas del mundo si la humanidad pierde su rumbo, si se olvidan las grandes motivaciones que hacen posible la convivencia, el sacrificio, la bondad. [...] Si una mala comprensión de nuestros propios principios a veces nos ha llevado a justificar el maltrato a la naturaleza o el dominio despótico del ser humano sobre lo creado o las guerras, la injusticia y la violencia, los creyentes podemos reconocer que de esa manera hemos sido infieles al tesoro de sabiduría que debíamos custodiar. Muchas veces los límites culturales de diversas épocas han condicionado esa conciencia del propio acervo ético y espiritual, pero es precisamente el regreso a sus fuentes lo que permite a las religiones responder mejor a las necesidades actuales. (200)

La mayor parte de los habitantes del planeta se declaran creyentes, y esto debería provocar a las religiones a entrar en un diálogo entre ellas orientado al cuidado de la naturaleza, a la defensa de los pobres, a la construcción de redes de respeto y de fraternidad. Es imperioso también un diálogo entre las ciencias mismas, porque cada una suele encerrarse en los límites de su propio lenguaje, y la especialización tiende a convertirse en aislamiento y en absolutización del propio saber. Esto impide afrontar adecuadamente los problemas del medio ambiente. También se vuelve necesario un diálogo abierto y amable entre los diferentes movimientos ecologistas, donde no faltan las luchas ideológicas. La gravedad de la crisis ecológica nos exige a todos pensar en el bien común y avanzar en un camino de diálogo que requiere paciencia, ascesis y generosidad, recordando siempre que "la realidad es superior a la idea". (201)

El MV propone una Ética de la ciudadanía global, el espacio público y los movimientos sociales. A su vez en LS se sostiene que,

[...] no basta que cada uno sea mejor para resolver una situación tan compleja como la que afronta el mundo 
actual. Los individuos aislados pueden perder su capacidad y su libertad para superar la lógica de la razón instrumental y terminan a merced de un consumismo sin ética y sin sentido social y ambiental. A problemas sociales se responde con redes comunitarias, no con la mera suma de bienes individuales: "Las exigencias de esta tarea van a ser tan enormes, que no hay forma de satisfacerlas con las posibilidades de la iniciativa individual y de la unión de particulares formados en el individualismo. Se requerirán una reunión de fuerzas y una unidad de realización". La conversión ecológica que se requiere para crear un dinamismo de cambio duradero es también una conversión comunitaria. (219)

No todos están llamados a trabajar de manera directa en la política, pero en el seno de la sociedad germina una innumerable variedad de asociaciones que intervienen a favor del bien común preservando el ambiente natural y urbano. Por ejemplo, se preocupan por un lugar común (un edificio, una fuente, un monumento abandonado, un paisaje, una plaza), para proteger, sanear, mejorar o embellecer algo que es de todos. A su alrededor se desarrollan o se recuperan vínculos y surge un nuevo tejido social local. Así una comunidad se libera de la indiferencia consumista. Esto incluye el cultivo de una identidad común, de una historia que se conserva y se transmite. De esa manera se cuida el mundo y la calidad de vida de los más pobres, con un sentido solidario que es al mismo tiempo conciencia de habitar una casa común que Dios nos ha prestado. Estas acciones comunitarias, cuando expresan un amor que se entrega, pueden convertirse en intensas experiencias espirituales. (232) Hace falta volver a sentir que nos necesitamos unos a otros, que tenemos una responsabilidad por los demás y por el mundo, que vale la pena ser buenos y honestos. Ya hemos tenido mucho tiempo de degradación moral, burlándonos de la ética, de la bondad, de la fe, de la honestidad, y llegó la hora de advertir que esa alegre superficialidad nos ha servido de poco. Esa destrucción de todo fundamento de la vida social termina enfrentándonos unos con otros para preservar los propios intereses, provoca el surgimiento de nuevas formas de violencia y crueldad e impide el desarrollo de una verdadera cultura del cuidado del ambiente. (229)

El amor, lleno de pequeños gestos de cuidado mutuo, es también civil y político, y se manifiesta en todas las acciones que procuran construir un mundo mejor. El amor a la sociedad y el compromiso por el bien común son una forma excelente de la caridad, que no sólo afecta a las relaciones entre los individuos, sino a "las macro-relaciones, como las relaciones sociales, económicas y políticas". [...] En este marco, junto con la importancia de los pequeños gestos cotidianos, el amor social nos mueve a pensar en grandes estrategias que detengan eficazmente la degradación ambiental y alienten una cultura del cuidado ${ }^{13}$ que impregne toda la sociedad. (231)

La propuesta de MV de una Ética de la gobernabilidad global y la democracia participativa, encuentra una ratificación en la siguiente afirmación hecha en LS:

Urgen acuerdos internacionales que se cumplan, dada la fragilidad de las instancias locales para intervenir de modo eficaz. Las relaciones entre Estados deben resguardar la soberanía de cada uno, pero también establecer caminos consensuados para evitar catástrofes locales que terminarían afectando a todos. Hacen falta marcos regulatorios globales que impongan obligaciones y que impidan acciones intolerables, como el hecho de que empresas o países poderosos expulsen a otros países residuos e industrias altamente contaminantes. (173)

En este contexto, se vuelve indispensable la maduración de instituciones internacionales más fuertes y eficazmente organizadas, con autoridades designadas equitativamente por acuerdo entre los gobiernos nacionales, y dotadas de poder para sancionar. Como afirmaba Benedicto XVI en la línea ya desarrollada por la doctrina social de la Iglesia, "para gobernar la economía mundial, para sanear las economías afectadas por la crisis, para prevenir su empeoramiento y mayores desequilibrios consiguientes, para lograr un oportuno desarme integral, la seguridad alimenticia y la paz, para garantizar la salvaguardia del ambiente y regular los flujos migratorios, urge la presencia de una verdadera Autoridad política mundial, como fue ya esbozada por mi Predecesor, [san] Juan XXIII”. En esta perspectiva, la diplomacia adquiere una importancia inédita, en orden a promover estrategias internacionales que se anticipen a los problemas más graves que terminan afectando a todos. (175)

\footnotetext{
${ }^{13}$ Como lo señala Leonardo Boff en su libro Saber cuidar. Ética do humano - compaixão pela Terra: "Todo lo que existe y vive precisa ser cuidado para continuar su existir y vivir: una planta, un animal, un niño, un anciano, el planeta Tierra. Una antigua fábula dice que la esencia del ser humano reside en el cuidado. El cuidado es más fundamental que la razón y la voluntad."
} 
De modo similar la Ética de los bienes comunes y del Bien Común demandada en el MV es reiterada cuando LS recuerda que,

El medio ambiente es un bien colectivo, patrimonio de toda la humanidad y responsabilidad de todos. Quien se apropia algo es sólo para administrarlo en bien de todos. Si no lo hacemos, cargamos sobre la conciencia el peso de negar la existencia de los otros. Por eso, los Obispos de Nueva Zelanda se preguntaron qué significa el mandamiento "no matarás" cuando "un veinte por ciento de la población mundial consume recursos en tal medida que roba a las naciones pobres y a las futuras generaciones lo que necesitan para sobrevivir". (95)

\section{Afirma asimismo que:}

La ecología integral es inseparable de la noción de bien común, un principio que cumple un rol central y unificador en la ética social. Es "el conjunto de condiciones de la vida social que hacen posible a las asociaciones y a cada uno de sus miembros el logro más pleno y más fácil de la propia perfección". (156)

En las condiciones actuales de la sociedad mundial, donde hay tantas inequidades y cada vez son más las personas descartables, privadas de derechos humanos básicos, el principio del bien común se convierte inmediatamente, como lógica e ineludible consecuencia, en un llamado a la solidaridad y en una opción preferencial por los más pobres. Esta opción implica sacar las consecuencias del destino común de los bienes de la tierra, pero, como he intentado expresar en la Exhortación apostólica Evangelii gaudium, exige contemplar ante todo la inmensa dignidad del pobre a la luz de las más hondas convicciones creyentes. Basta mirar la realidad para entender que esta opción hoy es una exigencia ética fundamental para la realización efectiva del bien común. (158)

Incluso LS realiza un radical juicio ético político cuando hace referencia al tema del agua, saliendo al paso a los procesos privatizadores realizados por muchos gobiernos e impulsado desde los circuitos tecno-burocráticos globales en las décadas recientes,
Mientras se deteriora constantemente la calidad del agua disponible, en algunos lugares avanza la tendencia a privatizar este recurso escaso, convertido en mercancía que se regula por las leyes del mercado. En realidad, el acceso al agua potable y segura es un derecho humano básico, fundamental y universal, porque determina la sobrevivencia de las personas, y por lo tanto es condición para el ejercicio de los demás derechos humanos. Este mundo tiene una grave deuda social con los pobres que no tienen acceso al agua potable, porque eso es negarles el derecho a la vida radicado en su dignidad inalienable. Esa deuda se salda en parte con más aportes económicos para proveer de agua limpia y saneamiento a los pueblos más pobres. Pero se advierte un derroche de agua no sólo en países desarrollados, sino también en aquellos menos desarrollados que poseen grandes reservas. Esto muestra que el problema del agua es en parte una cuestión educativa y cultural, porque no hay conciencia de la gravedad de estas conductas en un contexto de gran inequidad. $(30)^{14}$

Una mayor escasez de agua provocará el aumento del costo de los alimentos y de distintos productos que dependen de su uso. Algunos estudios han alertado sobre la posibilidad de sufrir una escasez aguda de agua dentro de pocas décadas si no se actúa con urgencia. Los impactos ambientales podrían afectar a miles de millones de personas, pero es previsible que el control del agua por parte de grandes empresas mundiales se convierta en una de las principales fuentes de conflictos de este siglo. (31) En toda discusión acerca de un emprendimiento, una serie de preguntas deberían plantearse en orden a discernir si aportará a un verdadero desarrollo integral: ¿Para qué? ¿Por qué? ¿Dónde? ¿Cuándo? ¿De qué manera? ¿Para quién? ¿Cuáles son los riesgos? ¿A qué costo? ¿Quién paga los costos y cómo lo hará? En este examen hay cuestiones que deben tener prioridad. Por ejemplo, sabemos que el agua es un recurso escaso e indispensable $y$ es un derecho fundamental que condiciona el ejercicio de otros derechos humanos. Eso es indudable y supera todo análisis de impacto ambiental de una región. (185)

En relación a la Ética de la diversidad cultural y de una política de la diferencia, en LS se sostiene que,

Por eso, la ecología también supone el cuidado de las riquezas culturales de la humanidad en su sentido más

${ }^{14}$ Las cursivas del párrafo son del texto original. 
amplio. De manera más directa, reclama prestar atención a las culturas locales a la hora de analizar cuestiones relacionadas con el medio ambiente, poniendo en diálogo el lenguaje científico-técnico con el lenguaje popular. Es la cultura no sólo en el sentido de los monumentos del pasado, sino especialmente en su sentido vivo, dinámico y participativo, que no puede excluirse a la hora de repensar la relación del ser humano con el ambiente. (143) La visión consumista del ser humano, alentada por los engranajes de la actual economía globalizada, tiende a homogeneizar las culturas y a debilitar la inmensa variedad cultural, que es un tesoro de la humanidad. Por eso, pretender resolver todas las dificultades a través de normativas uniformes o de intervenciones técnicas lleva a desatender la complejidad de las problemáticas locales, que requieren la intervención activa de los habitantes. Los nuevos procesos que se van gestando no siempre pueden ser incorporados en esquemas establecidos desde afuera, sino que deben partir de la misma cultura local. Así como la vida y el mundo son dinámicos, el cuidado del mundo debe ser flexible y dinámico. Las soluciones meramente técnicas corren el riesgo de atender a síntomas que no responden a las problemáticas más profundas. Hace falta incorporar la perspectiva de los derechos de los pueblos y las culturas, y así entender que el desarrollo de un grupo social supone un proceso histórico dentro de un contexto cultural y requiere del continuado protagonismo de los actores sociales locales desde su propia cultura. Ni siquiera la noción de calidad de vida puede imponerse, sino que debe entenderse dentro del mundo de símbolos y hábitos propios de cada grupo humano. (144.)

Muchas formas altamente concentradas de explotación y degradación del medio ambiente no sólo pueden acabar con los recursos de subsistencia locales, sino también con capacidades sociales que han permitido un modo de vida que durante mucho tiempo ha otorgado identidad cultural y un sentido de la existencia y de la convivencia. La desaparición de una cultura puede ser tanto o más grave que la desaparición de una especie animal o vegetal. La imposición de un estilo hegemónico de vida ligado a un modo de producción puede ser tan dañina como la alteración de los ecosistemas. (145)

En este sentido, es indispensable prestar especial atención a las comunidades aborígenes con sus tradiciones culturales. No son una simple minoría entre otras, sino que deben convertirse en los principales interlocutores, sobre todo a la hora de avanzar en grandes proyectos que afecten a sus espacios. Para ellos, la tierra no es un bien económico, sino don de Dios y de los antepasados que descansan en ella, un espacio sagrado con el cual necesitan interactuar para sostener su identidad y sus valores. Cuando permanecen en sus territorios, son precisamente ellos quienes mejor los cuidan. Sin embargo, en diversas partes del mundo, son objeto de presiones para que abandonen sus tierras a fin de dejarlas libres para proyectos extractivos y agropecuarios que no prestan atención a la degradación de la naturaleza y de la cultura. (146)

En relación al requerimiento de una Ética de la paz y del diálogo para la resolución de conflictos hecha en MV, es posible encontrar en LS las siguientes consideraciones,

Por otro lado, ninguna persona puede madurar en una feliz sobriedad si no está en paz consigo mismo. Parte de una adecuada comprensión de la espiritualidad consiste en ampliar lo que entendemos por paz, que es mucho más que la ausencia de guerra. La paz interior de las personas tiene mucho que ver con el cuidado de la ecología y con el bien común, porque, auténticamente vivida, se refleja en un estilo de vida equilibrado unido a una capacidad de admiración que lleva a la profundidad de la vida. $\mathrm{La}$ naturaleza está llena de palabras de amor, pero ¿cómo podremos escucharlas en medio del ruido constante, de la distracción permanente y ansiosa, o del culto a la apariencia? Muchas personas experimentan un profundo desequilibrio que las mueve a hacer las cosas a toda velocidad para sentirse ocupadas, en una prisa constante que a su vez las lleva a atropellar todo lo que tienen a su alrededor. Esto tiene un impacto en el modo como se trata al ambiente. Una ecología integral implica dedicar algo de tiempo para recuperar la serena armonía con la creación, para reflexionar acerca de nuestro estilo de vida y nuestros ideales, para contemplar al Creador, que vive entre nosotros y en lo que nos rodea, cuya presencia "no debe ser fabricada sino descubierta, develada". (225)

Respecto a la propuesta de una Ética del ser y el tiempo de la sustentabilidad hecha en MV, LS ofrece un camino de aproximación muy sugerente,

La espiritualidad cristiana propone un modo alternativo de entender la calidad de vida, y alienta un estilo de vida profético y contemplativo, capaz de gozar profundamente sin obsesionarse por el consumo. Es importante 
incorporar una vieja enseñanza, presente en diversas tradiciones religiosas, y también en la Biblia. Se trata de la convicción de que "menos es más". La constante acumulación de posibilidades para consumir distrae el corazón e impide valorar cada cosa y cada momento. En cambio, el hacerse presente serenamente ante cada realidad, por pequeña que sea, nos abre muchas más posibilidades de comprensión y de realización personal. La espiritualidad cristiana propone un crecimiento con sobriedad y una capacidad de gozar con poco. Es un retorno a la simplicidad que nos permite detenernos a valorar lo pequeño, agradecer las posibilidades que ofrece la vida sin apegarnos a lo que tenemos ni entristecernos por lo que no poseemos. Esto supone evitar la dinámica del dominio y de la mera acumulación de placeres. (222) La sobriedad que se vive con libertad y conciencia es liberadora. No es menos vida, no es una baja intensidad sino todo lo contrario. En realidad, quienes disfrutan más y viven mejor cada momento son los que dejan de picotear aquí y allá, buscando siempre lo que no tienen, y experimentan lo que es valorar cada persona y cada cosa, aprenden a tomar contacto y saben gozar con lo más simple. Así son capaces de disminuir las necesidades insatisfechas y reducen el cansancio y la obsesión. Se puede necesitar poco y vivir mucho, sobre todo cuando se es capaz de desarrollar otros placeres y se encuentra satisfacción en los encuentros fraternos, en el servicio, en el despliegue de los carismas, en la música y el arte, en el contacto con la naturaleza, en la oración. La felicidad requiere saber limitar algunas necesidades que nos atontan, quedando así disponibles para las múltiples posibilidades que ofrece la vida. (223)

La sobriedad y la humildad no han gozado de una valoración positiva en el último siglo. Pero cuando se debilita de manera generalizada el ejercicio de alguna virtud en la vida personal y social, ello termina provocando múltiples desequilibrios, también ambientales. Por eso, ya no basta hablar sólo de la integridad de los ecosistemas. Hay que atreverse a hablar de la integridad de la vida humana, de la necesidad de alentar y conjugar todos los grandes valores. La desaparición de la humildad, en un ser humano desaforadamente entusiasmado con la posibilidad de dominarlo todo sin límite alguno, sólo puede terminar dañando a la sociedad y al ambiente [...] (224) Estamos hablando de una actitud del corazón, que vive todo con serena atención, que sabe estar plenamente presente ante alguien sin estar pensando en lo que viene después, que se entrega a cada momento como don divino que debe ser plenamente vivido. Jesús nos enseñaba esta actitud cuando nos invitaba a mirar los lirios del campo y las aves del cielo, o cuando, ante la presencia de un hombre inquieto, "detuvo en él su mirada, y lo amó" $(M c 10,21)$. Él sí que estaba plenamente presente ante cada ser humano y ante cada criatura, y así nos mostró un camino para superar la ansiedad enfermiza que nos vuelve superficiales, agresivos y consumistas desenfrenados. (226)

\section{Conclusiones}

Considero necesario recordar que el Papa es sudamericano, argentino, es el primer Papa proveniente del Sur del planeta. Su historia personal está generacionalmente vinculada a las experiencias del período de la Guerra Fría, que tanto daño le hicieron a la Humanidad y al impacto de las doctrinas de Seguridad Nacional que tanto dolor y sufrimiento generaron al sur del Río Grande en nuestro continente. Conoció de cerca a los teólogos que dieron origen al movimiento intelectual llamado Teología de la Liberación, coincidió con ellos en muchos de sus juicios y actuaciones al interior de la Iglesia y discrepó también de las corrientes más influidas por el pensamiento marxista. Juan Carlos Scannone, jesuita argentino al igual que el Papa, ha señalado que "la teología del pueblo", una ramificación de la teología de la liberación, está “en la base de lo que está haciendo y diciendo el Papa Francisco". ${ }^{15}$

Lo que considero el mayor aporte de Laudato $\mathrm{Si}^{\prime}$ al diálogo ambiental es que lleva a cabo una revisión sistemática de la crisis desde un punto de vista religioso. Si bien ya existían aportes hechos desde este ámbito al diálogo del medio ambiente, ellos han tenido una relativa desconsideración en un debate enmarcado principalmente con el lenguaje político, científico y económico. Con esta nueva encíclica, el lenguaje de quienes profesan una fe entra decididamente en participar de una imprescindible y urgente discusión que se está llevando a cabo. Metafóricamente podríamos decir que estamos en presencia de un giro epistémico, que nos refiere a formas de

${ }^{15}<\mathrm{http}$ //www.europapress.es/sociedad/noticia-jesuita-scannone-asegura-teologia-pueblo-rama-teologia-liberacion-base-gestos-20150210133914. html $>$. 
pensamiento y acción inspiradas en las prácticas sociales de las luchas de nuestro continente. Silvia Riveiro ${ }^{16}$ en un artículo que dio cuenta del Segundo encuentro de movimientos populares con el papa Francisco, con más de mil 500 participantes de 40 países, realizado en Santa Cruz, Bolivia, del 7 al 9 de julio de 2015, señala que el cardenal Peter Turkson, presidente del Pontificio Consejo de Justicia y Paz:

retomó la encíclica, afirmando que los movimientos "se han organizado para resistir la exclusión social, la escandalosa desigualdad y la degradación del ambiente [...] No sólo protestan, también resuelven con sus propias manos los problemas de acceso a techo, trabajo y tierra, que ni estados ni mercados resuelven. [...] Ni la política ni la economía o la ecología son tarea exclusiva de profesionales, políticos, activistas o académicos. Los pobres, los campesinos, los pueblos indígenas tienen sus propias formas de hacer política en asambleas comunitarias, economía popular y para cuidar el ambiente, con ecología popular". Afirmó: acompañamos a los movimientos en la preocupación y luchas por los dones de la creación, tomando como ejemplo que "los movimientos luchan por la dignidad, contra el consumismo, el despilfarro y el paradigma tecnocrático [...] para "no ser explotados ni explotar, excluir o ser excluidos [...] Luchan contra el colonialismo y el saqueo de los llamados recursos naturales, para que no se privatice el agua, el subsuelo o el mar [...] para que las trasnacionales no abusen de la tierra con la megaminería y el fracking, ni que se usen transgénicos para exprimir los campesinos y concentrar la tierra en pocas manos, o se destruya la pesca artesanal". Llamó a escuchar el grito de la tierra y el grito de los pobres.

\section{$\mathrm{Y}$ dice que,}

El Papa afirmó los puntos en este segundo encuentro, y expresó que necesitamos un cambio estructural de sistema y modelo dominante, por la enorme injusticia socio-económica global, por la devastación de la madre tierra, por la dominación que ejerce una inmoral minoría financiera. Se pronunció contra los tratados de libre comercio, por ser un instrumento de esa dominación.
Entre otros puntos, llamó a los movimientos a seguir abonando el proceso de cambio que necesitamos, a seguir sembrando y regando esa semilla, y parafraseando a la Vía Campesina, a cambiar la globalización que nos está destruyendo por la globalización de la esperanza.

Confrontando a los que argumentan que una encíclica papal sobre el medio ambiente no tiene autoridad real, Francisco afirma explícitamente que Laudato Si "“se añade ahora al cuerpo de la doctrina social de la Iglesia." (15) Una encíclica es un tipo de enseñanza que cuenta con el más alto estatuto epistemológico en la iglesia, sólo superada por los Evangelios y los concilios realizados como el Vaticano II. Como tal, sigue el tipo de reflexión sobre los problemas sociales del presente iniciada por León XIII con la Rerum Novarum, en 1891. Francisco utiliza algunos de los fundamentos tradicionales de la enseñanza social católica, sobre todo la idea de "bien común", para enmarcar la discusión. En consonancia con las prácticas de la enseñanza social católica, el Papa combina el corpus de la teología de la iglesia con las conclusiones de los expertos en una variedad de campos, para reflexionar sobre los problemas de hoy en día. Con ese fin, vincula explícitamente su reflexión con la de Juan XXIII en Pacem in Terris, en que se aborda la crisis de la guerra nuclear.

La lectura detallada de los documentos analizados me permiten afirmar que: a) en la Encíclica Laudato $s i$ ' del papa Francisco recoge gran parte, sino toda, la reflexión que desde América Latina se ha venido haciendo en torno a los problemas de la sustentabilidad y de la justicia social; b) su planteo es un llamado a un profundo cambio de los ejes civilizatorios; c) su tono aparentemente catastrofista, expresa no obstante un profunda esperanza en que es posible torcer el rumbo y esboza los principales caminos para ello; d) recupera la figura de Francisco de Asís y marca con ello el camino que debería seguir la mayor institución del planeta: la Iglesia Católica; e) con un lenguaje sin ambigüedades critica a los poderes fácticos (económicos y políticos) que hoy gobiernan el mundo y a las conductas, creencias y actitudes de quienes los ejercen; f) propone una

\footnotetext{
${ }^{16}$ Silvia Ribeiro. "El grito de la tierra y el grito de los pobres" en ALAINET del 17/07/2015. Disponible en: $<$ http://www.alainet.org/es/ articulo/171168\#sthash.cJIUpDmE.dpuf>.
} 
conversión ecológica hacia la sobriedad, la humildad, la fraternidad, una nueva solidaridad universal y una cultura del cuidado; y g) convoca a difundir un nuevo

\section{Referencias}

Aguilera K. F. (Coord.). Para la rehumanización de la economía y la sociedad. Almería: Cajamar, 2013.

Boff, L. Ecología: grito de la tierra, grito de los pobres. Madrid: Trotta, 1996.

Boff, L. Saber cuidar. Ética do humano - compaixão pela Terra. Petrópolis: Vozes, 1999.

Carta de la Tierra, 2000. Disponible en: $<$ http://earthcharterinaction.org/contenido/pages/Lea\%201a\%20Carta\%20de\%20 la\%20Tierra>.

Francisco. Carta encíclica Laudato si'. Sobre el cuidado de la casa común. Disponible en: $<$ http://w2.vatican.va/content/fran- paradigma acerca del ser humano, la vida, la sociedad y la relación con la naturaleza.

cesco/es/encyclicals/documents/papa-francesco_20150524_ enciclica-laudato-si.html>.

Francisco. Exhortación apostólica Evangelii gaudium, 2013. Disponible en: <http://w2.vatican.va/content/francesco/es/ apost exhortations/documents/papa-francesco esortazione-ap_20131124_evangelii-gaudium.html $>$.

Manifiesto por la Vida. In: Leff, E. (Coord.) Etica, vida, sustentabilidad. México: PNUMA, 2002.

Maturana, H. Prólogo. In: Elizalde, A. Desarrollo humano y ética para la sustentabilidad. México: PNUMA, 2003. 